\title{
A novel formulation of theranostic nanomedicine for targeting drug delivery to gastrointestinal tract cancer
}

\author{
Madeeha Shahzad Lodhi ${ }^{*}$, Muhammad Tahir Khan ${ }^{1}$, Saira Aftab ${ }^{1}$, Zahoor Qadir Samra², Heng Wang ${ }^{3}$ and \\ Dong Qing Wei $\mathrm{i}^{3,4,5^{*}}$ (D)
}

\author{
*Correspondence: \\ madeeha.shahzad@imbb.uol. \\ edu.pk; dqwei@sjtu.edu.cn \\ ${ }^{1}$ Institute of Molecular \\ Biology and Biotechnology \\ (IMBB), The University \\ of Lahore, Defence Road \\ Lahore, Lahore Postal code: \\ 58810, Pakistan \\ ${ }^{3}$ State Key Laboratory \\ of Microbial Metabolism, \\ School of Life Sciences \\ and Biotechnology, \\ Shanghai, China \\ Full list of author information \\ is available at the end of the \\ article
}

\begin{abstract}
Background: Theranostic nanomedicines contain a nanovehicle that has fluorescent properties and can be used for diagnostic, therapeutic and prognostic purposes. The transferrin receptor expression is 1000-fold higher in rapidly growing cancer cells as compared to the normal cells and, therefore, can be used in targeted drug delivery systems. The objective of the present study was to design a novel targeted gold nanoparticle (GNPs)-based theranostic formulation for gastrointestinal (Gl) tract-related cancers. The synthesized GNPs were conjugated to transferrin and doxorubicin both separately and collectively to check their cytotoxic properties. The in vitro cytotoxicity of nanocomposites was observed against colon cancer cell line HCT-116. The doxorubicin conjugated nanocomposites showed almost the same cytotoxicity, but more effect at later hours (h). The $I C_{50}$ and $I C_{100}$ were $50 \mu \mathrm{g} / \mathrm{ml}$ and $250 \mu \mathrm{g} / \mathrm{ml}$, respectively, equivalent to the doxorubicin weight for GNP theranostic nanomedicine.
\end{abstract}

Results: The maximum effect was observed after $12 \mathrm{~h}$ and nanomedicines were still active after $72 \mathrm{~h}$ of treatment. Our in vivo data proved that nanomedicine crossed all the barriers and was successfully delivered to the tumour cells. Theranostic nanomedicine's (TNM) effect on body weight and survival rate on mice was many folds better than mice in pure doxorubicin group. It also showed almost $80 \%$ survival rate on day 40. The in vivo and in vitro results show the effects of prolonged drug release and the nanomedicine was not toxic to vital organs of the animal.

Conclusion: This is one of its kind studies in which a novel targeted nanomedicines approach was formulated for therapeutic as well as prognostic purposes against Gl tract cancer.

(c) The Author(s), 2021. Open Access This article is licensed under a Creative Commons Attribution 4.0 International License, which permits use, sharing, adaptation, distribution and reproduction in any medium or format, as long as you give appropriate credit to the original author(s) and the source, provide a link to the Creative Commons licence, and indicate if changes were made. The images or other third party material in this article are included in the article's Creative Commons licence, unless indicated otherwise in a credit line to the material. If material is not included in the article's Creative Commons licence and your intended use is not permitted by statutory regulation or exceeds the permitted use, you will need to obtain permission directly from the copyright holder. To view a copy of this licence, visit http:// creativecommons.org/licenses/by/4.0/. The Creative Commons Public Domain Dedication waiver (http://creativecommons.org/publi cdomain/zero/1.0/) applies to the data made available in this article, unless otherwise stated in a credit line to the data. 
Keywords: Theranostic nanomedicines, Gold nanoparticles, Transferrin, Targeted drug delivery, Gastrointestinal tract

\section{Introduction}

Theranostic is a novel terminology in the pharmaceutical industry, applied to products having both diagnostic and therapeutic properties (Chen et al. 2014). Designing the theranostic nanomedicines by combining the properties of diagnostic and therapeutic effects in one formulation is very useful in global public health issues. Nanoparticles (NPs) deliver the drug to cancerous cells for the maximum possible effect. They also increase drug retention as well as tumour vicinity time in the bloodstream, making them favourable even in passive targeted drug delivery (Cho et al. 2008). The role of targeted theranostic nanomedicines in drug delivery has a promising role to play.

The selection of nanovehicle and suitable ligand is very important for targeting drug delivery to cancer cells. Gold nanoparticles (GNP) are the most efficient to function as nanocarriers in prognostic, diagnostic as well as for cancer treatment purposes. Their fluorescent quenching properties (Verma et al. 2014) give them more edge over other NPs (Wolfbeis 2015).

In a previous study, the effect of surface moieties in attachment on negatively charged GNPs and has been investigated. The size of nanoparticles influences the emission energies, the shift of florescence intensities and peaks. To optimize the surface characteristics of GNPs, a suitable surface ligand may be attached to keep the size on the small side (Goldys and Sobhan 2012) of the final composite.

Targeted drug delivery (TDD) is important in cytotoxic effects minimization in all kinds of anticancer approaches. Another advantage is to release the drug in a controlled manner to avoid sudden adverse health effects of drugs (Langer 1998). There are many approaches of TDD for different cells and organs. The majority of these use membrane-bound cancer-specific antigens (Sudimack and Lee 2000). The involvement of nanocarriers has drastically changed the fate of TDL in the field of diagnostics and therapeutics (Singh and Lillard 2009); (Nagaich 2015).

Many of the cancer-specific cell surface receptors have many fold higher copy number on cancer cells as compared to the normal cells, for example transferrin receptor (Daniels et al. 2006a); (Jones et al. 2006). It is involved in the uptake of iron for hyperbiological activities like uncontrolled cell growth in cancer. Therefore, the transferrin receptor is very important in TDD of cancer for nanomedicines.

Gastric cancer is the third most deadly cancer (epidemiology of gastric cancer: global trends, risk factors and prevention), thereby necessitating an urgent need to establish a specific targeted therapy that acts only on cancerous cells. Targeted drug delivery with theranostic nanomedicines may be useful to overcome many problems in the diagnosis and treatment of cancer, usually common with trivial medicines.

The current study covers the development of novel theranostic nanomedicines using GNP as the nanovehicle for targeting drug delivery on cancerous cells. The diagnostic, prognostic, bioimaging, and therapeutic abilities of GNP theranostic nanomedicines were investigated in this study by using in vivo and in vitro approaches. 
The cysteine-capped GNP (nanocarriers) coupled with ligand transferrin protein and doxorubicin have potential to treat gastric cancer and can be a promising drug in the near future.

\section{Results}

\section{Characterization of GNP theranostic nanomedicine}

Binding efficiency (conjugates stoichiometry)

Stoichiometric analysis showed that 173.04 gold atoms were presented in a single gold nanoparticle and a total of $1.232 \times 10^{18} \mathrm{GNPs}$ were synthesized in a single batch. Calculations showed that approximately 115 cysteine capped a single GNP approximately $15 \mathrm{~nm}$ in size and a total of $1.42 \times 10^{20}$ were presented in a single batch of GNP. Doxorubicin binding efficiency to cysteine on GNP was 61.5\%. Calculations from precoupling and post-coupling doxorubicin solution showed that $41.85 \mathrm{mg}$ doxorubicin was conjugated to $50 \mathrm{mg}$ of particles. Lastly, the GNP theranostic nanomedicines were suspended in $5 \mathrm{ml}$ of deionized water, so the final concentration of doxorubicin conjugate to GNP was $8 \mu \mathrm{g} / \mu \mathrm{l}$, protein conjugated efficiency was $93 \%$ and total $130.5 \mu \mathrm{g}$ of transferrin conjugated to $50 \mathrm{mg}$ cysteine-capped GNP. Schematic synthesis and model of GNP theranostic nanomedicines and intermediate nanocomposites are shown in Fig. 2.

\section{UV-Vis spectrophotometry}

UV spectroscopy is an important strategy for the characterization of the nanoparticles during formulations. The colloidal GNP in liquid suspension showed maximum absorbance with single peak at $520 \mathrm{~nm}$ (Fig. 1a) and GNP-Cys at $520 \mathrm{~nm}$ (Fig. 1b). After conjugation of GNP-Cys with doxorubicin, a new UV spectrum was obtained with two peaks-one organic at $290 \mathrm{~nm}$ and another inorganic at $510 \mathrm{~nm}$ (Fig. 1c). UV spectrum of GNP theranostic nanomedicine (after conjugation with transferrin) showed a red shift in peak; the inorganic peak now appeared at $525 \mathrm{~nm}$ and the organic peak at $340 \mathrm{~nm}$ (Fig. 1d).

\section{Excitation and emission spectra}

GNP and all of its nanocomposites showed emission peak with different peak intensities when excited at specific wavelength. Nanocomposites were excited in the range of 359-364 nm and maximum emission was recorded. Bare GNP had the highest emission intensity 168.9 (Fig. 1g) that decreased after conjugations; the final emission intensity was noted as 116.2 (Fig. 1h). Fluorescent properties of nanoparticles were further observed under UV (excitation $350 \mathrm{~nm}$ with blue emission $450 \mathrm{~nm}$ ), blue (excitation $450 \mathrm{~nm}$ with green emission $550 \mathrm{~nm}$ ) and green filters of fluorescent microscope (excitation $550 \mathrm{~nm}$ with deep red emission $690 \mathrm{~nm}$ ). Fluorescence of GNP and GNP-CYS appeared only in blue and green emission filter, while after conjugation to doxorubicin (Fig. 1i), the last two nanocomposites' fluorescence also appeared in the red emission filter (Fig. 1f). 


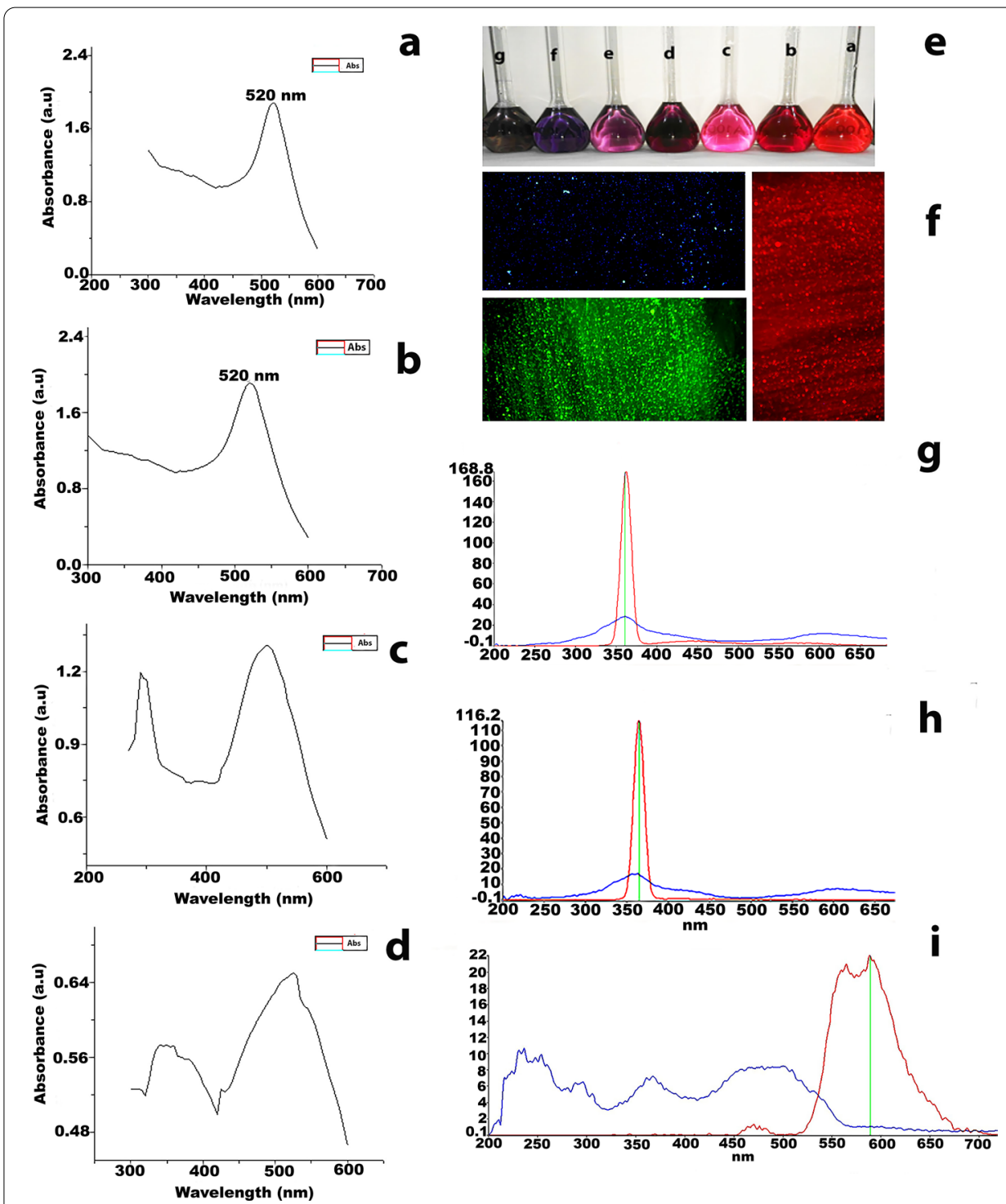

Fig. 1 UV spectroscopy analysis. a GNP spectrum shows maximum absorbance and peak at $520 \mathrm{~nm}$, b GNPCys at $520 \mathrm{~nm}, \mathbf{c}$ GNP-Cys-Dox at $510 \mathrm{~nm}$ and at $290 \mathrm{~nm}$. d UV spectrum of GNP theranostic nanomedicines shows a red shift in peak and now the inorganic peak with maximum absorption is at $525 \mathrm{~nm}$ with absorption 0.650 and organic peak is at 340 with absorption 0.573. e Optical properties of gold nanoparticles with different sizes: a 10, b 25, c 50, d 70, e 100,f $>100, \mathbf{g}>500$. f Final GNP theranostic nanomedicine shows the fluorescence under UV excitation, blue excitation and green excitation filters with strong fluorescence in blue filter. $\mathbf{g}, \mathbf{h}$ Excitation and emission spectra of GNP and nanomedicine show emission at $362.3 \mathrm{~nm}$ with different intensities 168.9 for GNP and 116.2 for GNP theranostic nanomedicine

\section{FTIR analysis for GNP nanocomposites}

GNP synthesis and conjugation of cysteine, doxorubicin and transferrin to GNP were studied by FTIR spectroscopy analysis. Figure 2a, b shows the FTIR spectra of cysteine and doxorubicin with characteristic peaks, respectively. In GNP FTIR spectroscopy analysis (Fig. 2c), the appearance of specific peaks proved the successful reaction of reduction between gold salt and citric acid. The formation of dicarboxy acetone was observed by the appearance of a stretching peak at $1634.55 \mathrm{~cm}^{-1}$-the indication of 


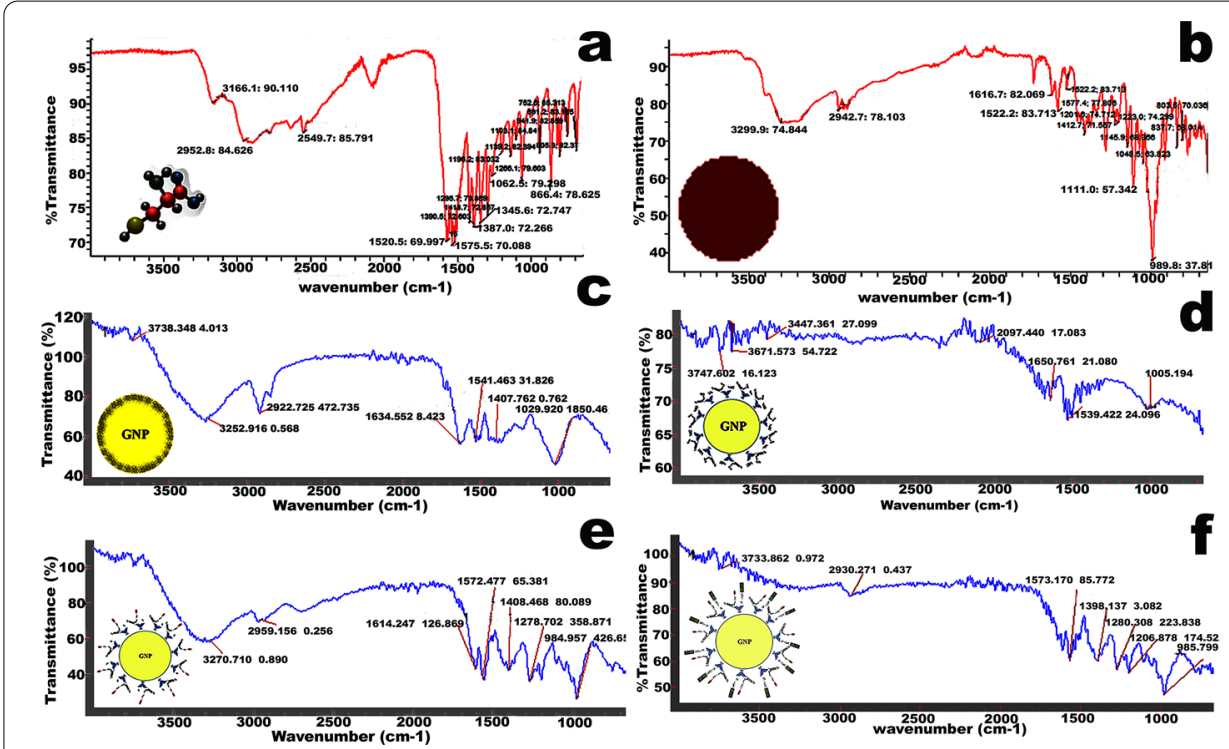

Fig. 2 FTIR spectroscopy analysis. FTIR spectra of cysteine shows the characteristics peaks of cysteine at position $752.5 \mathrm{~cm}^{-1} \mathrm{CH}_{2}$ rock, at $805.3 \mathrm{~cm}^{-1} \mathrm{COO}$ wagg, at $866.4 \mathrm{~cm}^{-1} \mathrm{~N}-\mathrm{O}$ stretch, at $941.9 \mathrm{~cm}^{-1} \mathrm{SH}$ bend, at $1062.5 \mathrm{~cm}^{-1} \mathrm{NH}_{3}$ rock, at $1139.2 \mathrm{~cm}^{-1} \mathrm{SO}_{2}$ stretch, at $1196.2 \mathrm{~cm}^{-1} \mathrm{CH}_{2}$ twist, at $1295.7 \mathrm{~cm}^{-1} \mathrm{CH}_{2}$ wagg, at $1345.6 \mathrm{~cm}^{-1} \mathrm{NH}_{3}$ bend, at $1418.7 \mathrm{~cm}^{-1} \mathrm{CH} 2$ bend, at $1520.5 \mathrm{~cm}^{-1} \mathrm{~N}=\mathrm{O}$ stretch, $1575.5 \mathrm{~cm}^{-1} \mathrm{NH}_{3}$ bend, at $2549.7 \mathrm{~cm}^{-1} \mathrm{SH}$ stretch and at $2952.9 \mathrm{~cm}^{-1} \mathrm{CH} 2$ stretch. FTIR spectra of free doxorubicin hydrochloride shows the characteristics peaks of doxorubicin including strong stretch of primary alcohol at $989.8 \mathrm{~cm}^{-1}$ and other stretching peaks of alcoholic groups at $1000-1150 \mathrm{~cm}^{-1}$, amine stretching at $3299.9 \mathrm{~cm}^{-1}$, alkane stretch at $2942.7 \mathrm{~cm}^{-1}$, aromatic group stretch peaks in area $1412-1616 \mathrm{~cm}^{-1}, \mathrm{C}-\mathrm{O}-\mathrm{C}$ stretch of ether at position $1283.1 \mathrm{~cm}^{-1}$ and $\mathrm{C}=\mathrm{O}$ stretch of ketone at $1730.2 \mathrm{~cm}^{-1}$. FTIR spectroscopic analysis of GNP shows the spinal structure of GNP. The peak at $1634.55 \mathrm{~cm}^{-1}$ represents the ketonic carbon oxygen double bond. The peak at $1541.46 \mathrm{~cm}^{-1}$ represents the $\mathrm{R}-\mathrm{CO}_{2}$ stretching, $1029.92 \mathrm{~cm}^{-1}$ is the $\mathrm{C}-\mathrm{O}$ stretching and the peak at $3252.916 \mathrm{~cm}^{-1}$ represents the $\mathrm{O}-\mathrm{H}$ group stretching. FTIR spectroscopic analysis of GNP-cysteine shows the successful incorporation of cysteine on GNP. The disappearance of S-H peak at $2549.7 \mathrm{~cm}^{-1}$ and the appearance of cysteine functional group amine $\mathrm{N}-\mathrm{H}$ stretch at $3447.36 \mathrm{~cm}^{-1}, \mathrm{~N}-\mathrm{H}$ bend at area $1580-1650 \mathrm{~cm}^{-1}$, carboxylic group $C=0$ stretch at $1650.76 \mathrm{~cm}^{-1}$ and $C-O$ stretch at $1005.19 \mathrm{~cm}^{-1}$ confirm the conjugation of cysteine with GNP. FTIR spectroscopic analysis of GNP-cysteine-doxorubicin shows the successful conjugation of doxorubicin with cysteine carboxylic group on GNP. The disappearance of $C=O$ stretch at 1650.761 and C-O stretch at 1005.194 of GNP-Cys spinal structure and appearance of amide bond (C-N) stretching peak at 1278.702 and doxorubicin-specific peaks confirm the conjugation of doxorubicin with GNP-Cys nanoparticles. FTIR spectroscopic analysis of GNP-cysteine-doxorubicin-transferrin shows the successful conjugation of transferrin with cysteine amine group on GNP. The disappearance of $\mathrm{N}-\mathrm{H}$ stretching peak at position 3270.710 and N-H bent at 1614.247 of GNP-Cys-Dox spinal structure confirm the conjugation of doxorubicin with GNP-Cys-Dox nanoparticles

ketonic carbon oxygen double bonds. The peaks at $1541.46 \mathrm{~cm}^{-1}$ and $1029.92 \mathrm{~cm}^{-1}$ signify the reduction of gold salt with citric acid. The peak at $1541.46 \mathrm{~cm}^{-1}$ represented the $\mathrm{R}_{-} \mathrm{Co}_{2}$ stretching, the peak at $1029.92 \mathrm{~cm}^{-1}$ was the $\mathrm{C}-\mathrm{O}$ stretching and peak at $3252.91 \mathrm{~cm}^{-1}$ showed the $\mathrm{O}-\mathrm{H}$ group stretching of carboxylic acid. In FTIR spectra of GNP conjugated with cysteine (Fig. 2d), the disappearance of the specific thiol peak of cysteine at $2549.70 \mathrm{~cm}^{-1}$ confirmed the successful binding of cysteine linker at GNP. On the other hand, many peaks specific to GNP disappeared and new peaks were observed in FTIR analysis of GNP-Cys conjugates. In GNP-Cys FTIR spectra, the characteristic peaks of cysteine were observed at the spinal structure of GNP; the most important one was seen at $3447.36 \mathrm{~cm}^{-1}$ which represented the $\mathrm{N}-\mathrm{H}$ stretch of primary and secondary amines. The mild peaks of the $\mathrm{N}-\mathrm{H}$ bend of amines were seen in the area defined by 
$1580-16 \mathrm{~cm}^{-1}$. The carboxylic group $\mathrm{C}=\mathrm{O}$ stretch was seen at $1650.76 \mathrm{~cm}^{-1}$ and $\mathrm{C}-\mathrm{O}$ stretch was observed at $1005.19 \mathrm{~cm}^{-1}$. In GNP-Cys-Dox FTIR spectra (Fig. 2e), the disappearance of $\mathrm{C}=\mathrm{O}$ stretch at $1650.76 \mathrm{~cm}^{-1}$ and $\mathrm{C}-\mathrm{O}$ stretch at $1005.19 \mathrm{~cm}^{-1}$ of GNPCys spinal structure was seen with the appearance of amide bond $(\mathrm{C}-\mathrm{N})$ stretching peak at $1278.70 \mathrm{~cm}^{-1}$-thus confirming the conjugation of doxorubicin with GNP-Cys nanoparticles. The strong N-H stretching peak of cysteine was still observed at $3270.71 \mathrm{~cm}^{-1}$ in the new FTIR spectra with $\mathrm{N}-\mathrm{H}$ bend at position $1614.24 \mathrm{~cm}^{-1}$. The characteristic peaks of doxorubicin were also observed at positions where they were seen in free doxorubicin with slight shifts. New FTIR spectra showed strong stretching peak of primary alcohol at $984.95 \mathrm{~cm}^{-1}$, alkane stretch at $2959.15 \mathrm{~cm}^{-1}$, aromatic group stretching peaks at position $1408.46 \mathrm{~cm}^{-1}$ and $\mathrm{C}-\mathrm{O}-\mathrm{C}$ stretch ether at position $1278.70 \mathrm{~cm}^{-1}$. The fourth reaction involved the conjugation of amine group of transferrin protein with the amine group of third composite by double glutaraldehyde method (Fig. 2c). The conjugation of transferrin to third composite was confirmed by the disappearance of the strong $\mathrm{N}-\mathrm{H}$ stretch of amine group at position $3270.71 \mathrm{~cm}^{-1}$ and $\mathrm{N}-\mathrm{H}$ bend at position $1614.24 \mathrm{~cm}^{-1}$ on GNP-Cys-Dox spinal structure. The transferrin protein conjugation was confirmed by shifting of the old peaks and appearance of new peaks due to the successful conjugation of transferrin on amine group through $\mathrm{N}-\mathrm{N}$ linkage.

\section{Dynamic laser scattering analysis}

DLS analysis of particles showed the size and dispersity of GNP nanocomposites. All nanoparticles showed monodispersity and narrow size range except doxorubicin conjugated nanocomposites which showed small aggregations and was reversed after protein conjugation. DLS analysis of GNP showed nanoparticles distribution in size range of $20 \mathrm{~nm}$ to $30 \mathrm{~nm}$ with mean size of $25 \mathrm{~nm}$ (Fig. 3b); cysteine-capped GNP showed size range of $20 \mathrm{~nm}$ to $35 \mathrm{~nm}$ with mean size of $30 \mathrm{~nm}$ (Fig. 3c). Doxorubicin conjugated cysteine-capped GNP showed nanoparticles in the size range of $200 \mathrm{~nm}$ to $380 \mathrm{~nm}$ due to aggregation of particles (Fig. 3d). After transferrin conjugation to nanocomposites, size was observed in the range of 100 to $150 \mathrm{~nm}$ with mean size of $98 \mathrm{~nm}$ polydispersity index (PI) of 0.214 (Fig. 3e).

\section{Transmission electron microscopy}

The size of synthesized GNPs was also characterized by transmission electron microscope. Figure 3f shows the synthesized naked GNP uniformly distributed, spherical in shape and with the mean size of $13 \mathrm{~nm}$. After conjugation with cysteine, the shape of the GNP-Cys nanocomposites remained spherical and the size did not increase; alternatively, an even more refined size distribution of $14 \mathrm{~nm}$ was observed (Fig. 3g). Third nanocomposites after conjugation of doxorubicin with cysteine on GNP showed an increase in the size of nanoparticles by about 25 to $50 \mathrm{~nm}$ and the mean size was $45 \mathrm{~nm}$; the shapes of particles were still spherical, but particles tend to come closer. The shape of the particles and selected area electron diffraction (SAED) pattern gave a clear indication of successful coating of particles with doxorubicin as well as of the crystalline nature of nanocomposite (Fig. 3h). After the final conjugation with transferrin, the nanocomposites' shape, size, SAED pattern and trend of particles are shown in Fig. 3i. The particles 


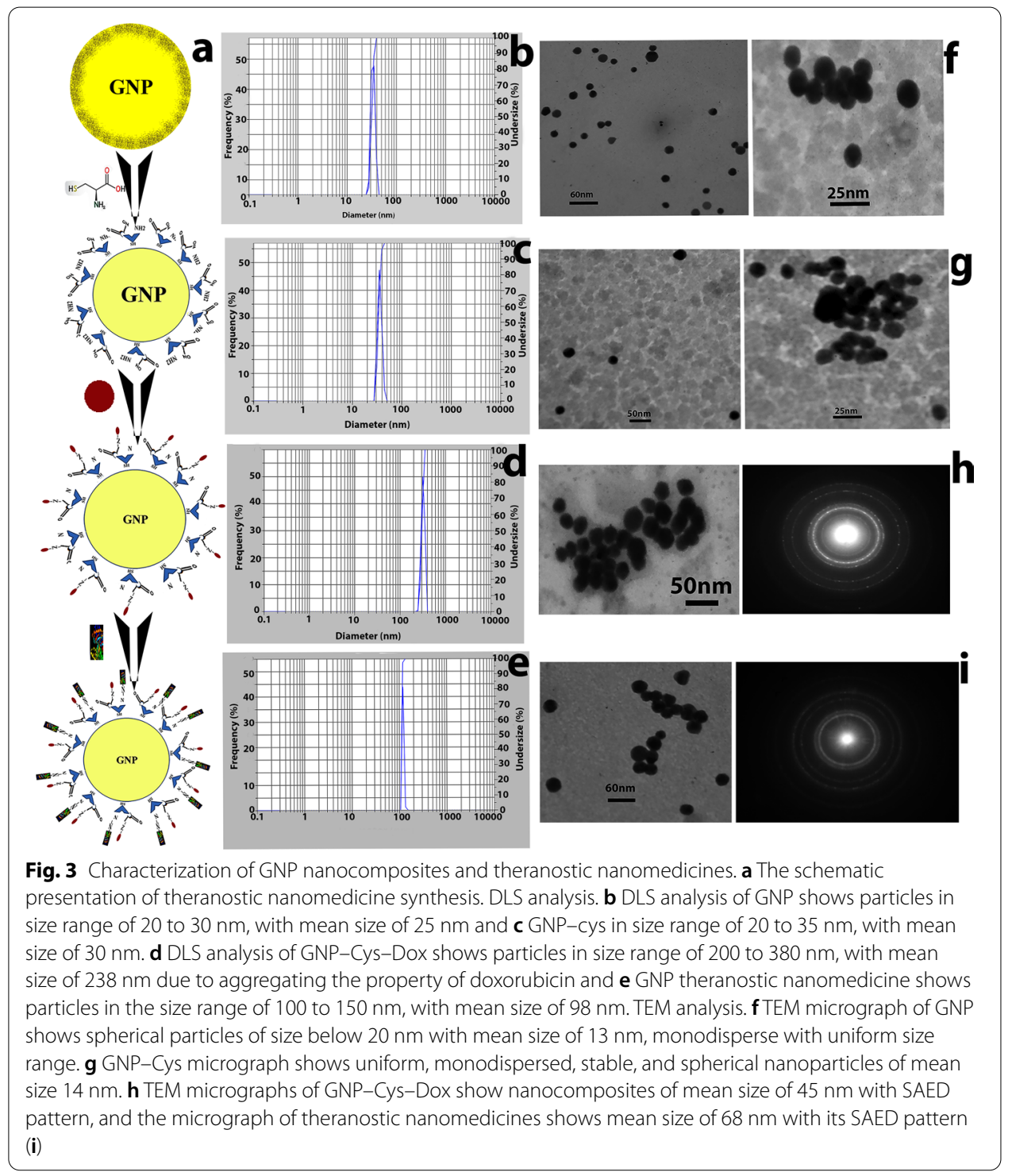

with light outer shade indicated the successful conjugation of protein on third nanocomposites. It also indicated that the nanocomposites are stabilized monodispersed particles with the final mean size of $68 \mathrm{~nm}$ and polycrystalline in nature.

\section{Cellular cytotoxicity with different GNP nanocomposites}

Three GNP nanocomposites in lower concentration $(1 \mu \mathrm{g} / \mu \mathrm{l})$ stock was taken, as $5 \mu \mathrm{l} / \mathrm{ml}$ of medium (5 $\mu \mathrm{g} / \mathrm{ml})$ (GNP-Cys, GNP-Cys-Dox and GNP-Cys-Dox-transferrin) and tested against colon cancer cell line and statistically (ANOVA) compared to see the therapeutic effect of nanocomposites. The GNP-Cys showed a toxic effect on cancer cells, but only on $8 \%$ with $92 \%$ cell viability. GNP-Cys-Dox and GNP theranostic nanomedicines proved more toxic due to the conjugation of doxorubicin, and cell viability was almost same in both composites (Fig. 4a). GNP-Cys-Dox showed $83 \%$ cell viability after transferrin conjugation and a little difference in cell viability was observed (80\%). Observation of cell morphology showed that even adherent cells were not in good shape due 


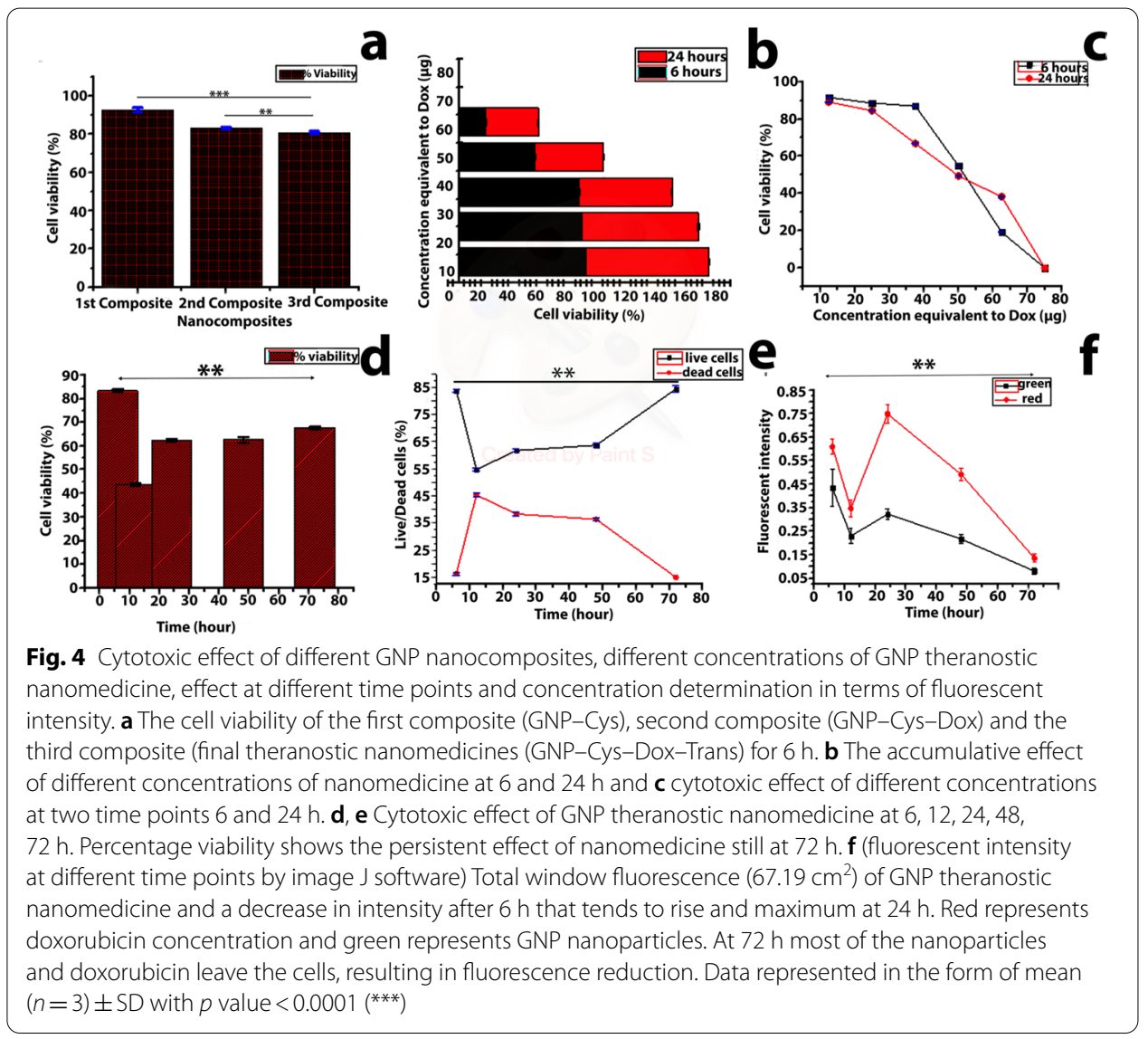

to the longer presence of nanomedicine. Data lied in confidence interval and showed the significance of comparison.

\section{Dose selection for GNP}

Different concentrations of GNP theranostic nanomedicines equivalent to different concentrations of doxorubicin were checked against colon cancer cells at $6 \mathrm{~h}$ and $24 \mathrm{~h}$ incubation. This assay was used to check the optimized time for GNP nanomedicine effect and optimum concentration for further assays. It was also used to get the IC 50 value and IC 100 value for GNP theranostic nanomedicines. Statistical comparison $(n=3)$ of mean value of cell viability, neutral red assay absorbance and percentage viability of different concentrations are shown in Fig $4 \mathrm{~b}$, c. Inhibitory concentration $50\left(\mathrm{IC}_{50}\right)$ for GNP nanomedicine was $50 \mu \mathrm{g} / \mathrm{ml}$ and $\mathrm{IC}_{100}$ was $500 \mu \mathrm{g} / \mathrm{ml}$ for our experiments. Figure $4 \mathrm{~b}$ shows that the accumulative effect of the drug at two time points -6 and $24 \mathrm{~h}-$ at different concentrations. The cell cytotoxicity was observed in a dose-dependant manner with increasing concentration of drug used (Fig. 4c). The statistical analysis was performed by ANOVA for group data and data lied in confidence interval with $p$ value $<0.0001$.

\section{Cellular cytotoxicity and drug binding}

Cellular cytotoxicity was observed in terms of cell viability and relative number of live and dead cells compared at different time points $(6 \mathrm{~h}, 12 \mathrm{~h}, 24 \mathrm{~h}, 48 \mathrm{~h}$ and 76). 

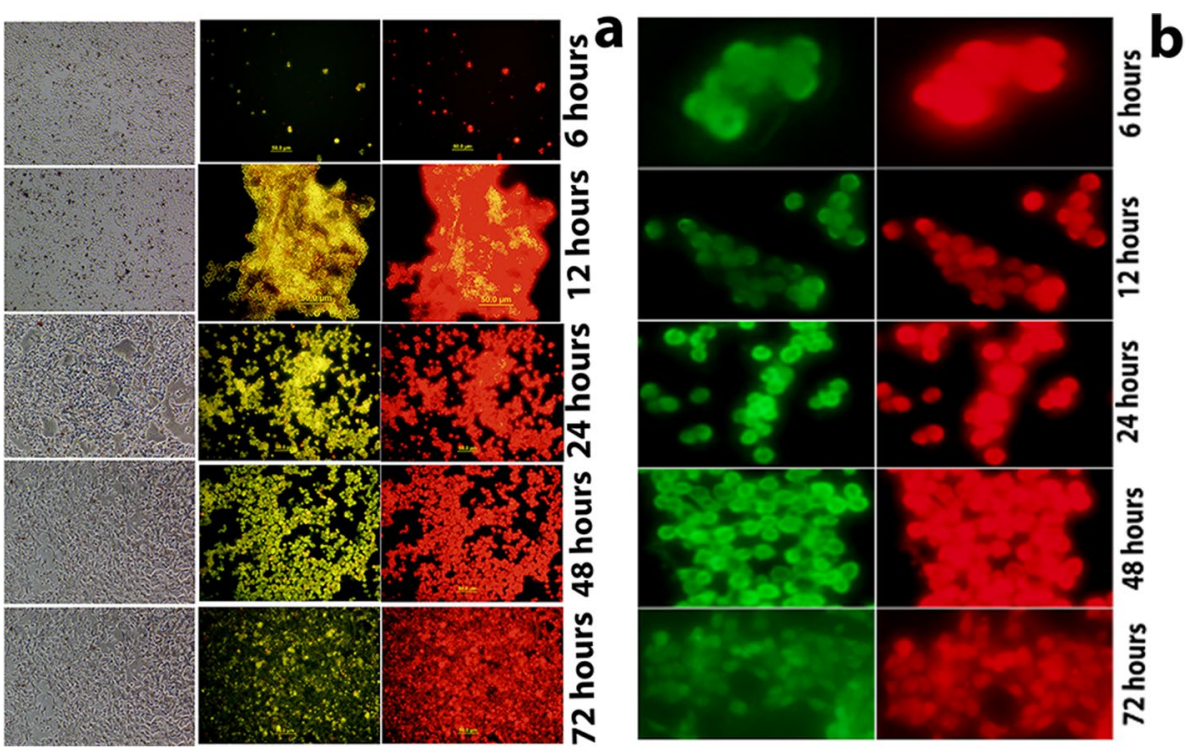

Fig. 5 Growth, cellular morphology and fluorescence study of GNP theranostic nanocomposites at different time points. a The growth, cellular morphology and the fluorescence under different filters. Green colour shows the presence of nanoparticles, while red fluorescence is due to doxorubicin. Examination confirmed the prolonged drug presence with controlled drug release even at $72 \mathrm{~h}$. b Intracellular tracking, receptor binding and intracellular localization of GNP theranostic nanomedicine that cause variation in binding and fluorescent intensities correlated to nanoparticles and doxorubicin concentration at 6, 12, 24, 48, and $72 \mathrm{~h}$

After each time point, the culture plate was observed under inverted and fluorescent microscope to observe the cell morphology and drug binding to the cell surface by fluorescence emission of GNPs and doxorubicin. Cells started to show changes in cellular morphology as compared to the untreated samples, and the same pattern was observed until the last time point $(76 \mathrm{~h})$. The overall cell morphology was round and shrunken. A pale area from the boundaries around the cell was prominent. The microscopy revealed the drug binding only on cell surface rather than in intercellular spaces in the medium, proving successful drug binding to the cell surface. Fluorescent microscopy proved the successful drug delivery after $6 \mathrm{~h}$ of post-treatment by the presence of doxorubicin inside the nucleus of the cancer cell (Fig. 5a). After $6 \mathrm{~h}$ post-treatment, the cells started to clump up and showed an increase in GNP and doxorubicin concentration. Fluorescence intensified after $12 \mathrm{~h}$ post-treatment and a magnified image showed the separation of nanoparticles from doxorubicin. Most of the doxorubicin was found in the nucleus of cells, while nanoparticles were observed in cytoplasm. After $24 \mathrm{~h}$ post-treatment, the doxorubicin killed the majority of the cells and was released in the medium as a result of cell membrane damage. At this point, the cells started to lose fluorescence and after $72 \mathrm{~h}$ post-treatment, the cells appeared faded under the fluorescent microscope. This cell cytotoxicity study showed that the GNP-based theranostic nanomedicine was effective even at $72 \mathrm{~h}$ due to the slow release of doxorubicin. Viability study showed different effects of the drug at different time points. It was most effective at $12 \mathrm{~h}$ and $24 \mathrm{~h}$ posttreatment. It was also effective at other points too but to a lesser extent. At $6 \mathrm{~h}$, the viability was only $83 \%$ and at $12 \mathrm{~h}$ it was $43 \%$. Mean comparison of cell viability at 


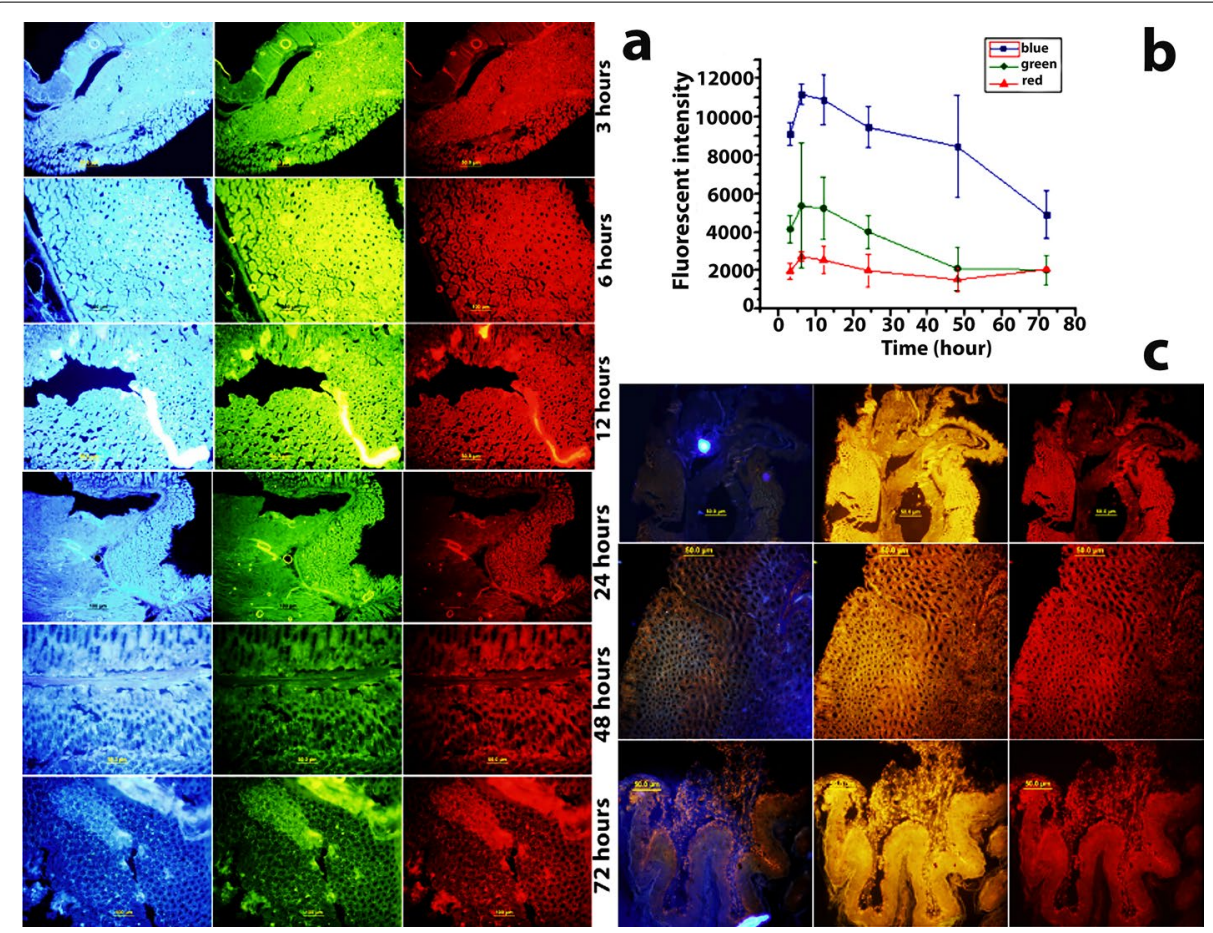

Fig. 6 In vivo and vitro receptor binding of GNP theranostic nanomedicine on gastric cancer tissues. Fluorescence in different filters (c) shows the presence of GNP nanoparticles and doxorubicin in tissue. Fluorescence only in tissue portion and not on slide showed receptor targeting and binding of theranostic nanomedicine to tissue. Nanocomposites due to doxorubicin presence give golden fluorescence under blue excitation filter. a The cellular tracking of GNP theranostic nanomedicine in vivo at different time points. Figure shows GNP theranostic nanomedicine binds to the receptor with different intensities at different time points. Maximum binding can be seen at $12 \mathrm{~h}$ and the most affected portions show the presence of more drugs. The concentration of nanoparticles and drug reduces after $12 \mathrm{~h}$ and at $48 \mathrm{~h}$ and, at $72 \mathrm{~h}$, traces remain with still some nanomedicine at the most affected portions. b (fluorescent intensity graph) The maximum binding of nanomedicines to receptor at $6 \mathrm{~h}$ that gradually reduces. Nanoparticles give blue and green, and doxorubicin gives red fluorescence. Intensity calculation is shown

different time points demonstrated that the data were within the significance interval with $p$ value $<0.0001$ (Fig. 4d). Comparison of live-dead cells also verified the viability study of strong medicine that action was at $12 \mathrm{~h}$ and remained still after 72 h (Fig. 4e).

\section{Intracellular GNP and doxorubicin tracking}

Image J software was used to reduce the counter fluorescence for the GNP and doxorubicin fluorescence independently. By this method, the GNP and doxorubicin were tracked inside cells as shown in Fig. 5b. Most of the nanomedicine drug dose was bound to cells after $6 \mathrm{~h}$ and showed fluorescence on whole cell surface. After $12 \mathrm{~h}$ post-treatment, the cells gave sharp combined fluorescence but it was decreased after subtracting the counter fluorescence, thereby showing that most of the doxorubicin, still associated with GNP. After $12 \mathrm{~h}$, doxorubicin was not only tracked inside the nucleus but also in cytoplasm with GNP. After 24- and 48-h post-treatment, most of the doxorubicin was located inside the nucleus and GNP in cytoplasm 

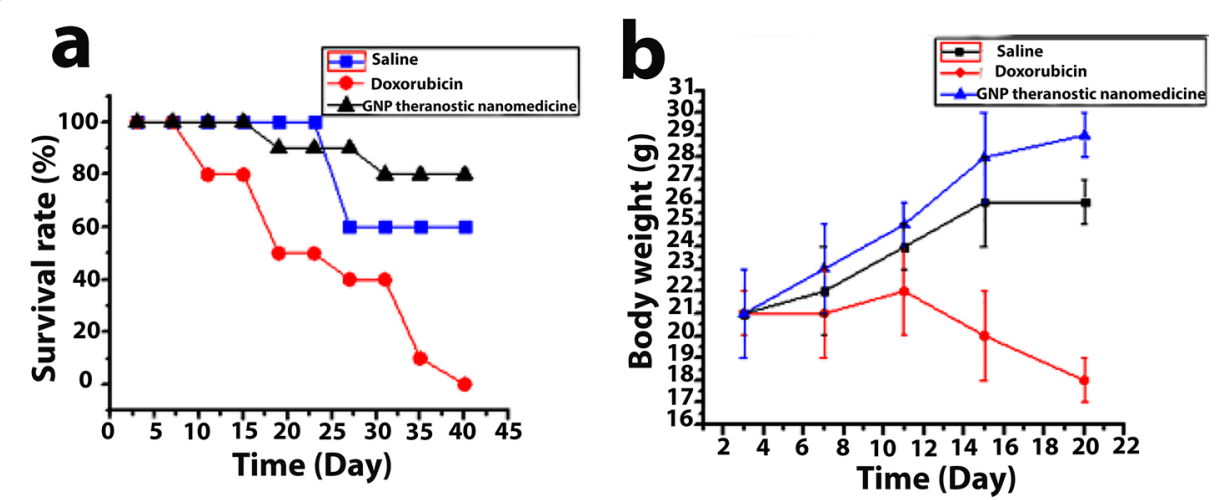

Fig. 7 Antigastric cancer efficacy of GNP theranostic nanomedicines during treatment in vivo. a The survival rates (\%) of the three groups of induced gastric cancer mice during 40 days treatment in the ten mice in each group and $\mathbf{b}$ the changes in body weight of different groups of mice over the period of 15 days observations

and, after $72 \mathrm{~h}$, the concentration inside cells started to vanish. Green fluorescent intensity was in proportion to the amount of GNP nanoparticles and red fluorescent intensity was in proportion to doxorubicin amount. Twenty cells in each group were used to calculate intensity and their means were compared by ANOVA. Figure $4 \mathrm{f}$ shows that the higher intensity points were $6 \mathrm{~h}$ and $12 \mathrm{~h}$, and the intensity started to reduce after $24 \mathrm{~h}$. Data were at significant intervals with $p$ value $<0.0001$.

\section{GNP binding to receptor on gastric cancer tissue (in vitro)}

Gastric tissue cryosection was incubated with GNP theranostic nanomedicine to check the binding ability of nanomedicine to target tissue in vitro. Figure $6 \mathrm{c}$ shows the successful binding of GNP theranostic nanomedicine to transferrin receptors on gastric tissue. Fluorescence in the blue and green filters showed the GNP nanoparticles present in tissue, while red fluorescence confirmed doxorubicin in tissue. GNP theranostic nanomedicines showed the successful and strong binding to transferrin receptors on gastric cancer tissue. Binding also confirmed that the formulation did not affect the transferrin binding to transferrin receptors and can be used in vivo to check drug efficacy.

\section{Therapeutic efficacy of GNP (in vivo)}

Therapeutic efficiency, delivery, receptor binding ability and intracellular drug tracking of theranostic drugs were checked on gastric cancer/tumour. Treated tissues were examined ex vivo by immunohistochemistry. GNP theranostic nanomedicine in concentration equivalent to $5 \mathrm{mg} / \mathrm{kg}$ doxorubicin was given orally through oral gavages to check the therapeutic effect and intracellular drug approach.

\section{Receptor binding and drug release}

Receptor binding activity and intracellular cell tracking of tissue were observed by ex vivo immunohistochemical studies of gastric tissue collected after 3, 6, 12, 24, 48 and $72 \mathrm{~h}$ of oral administration of GNP theranostic nanomedicine. Nanomedicine was 


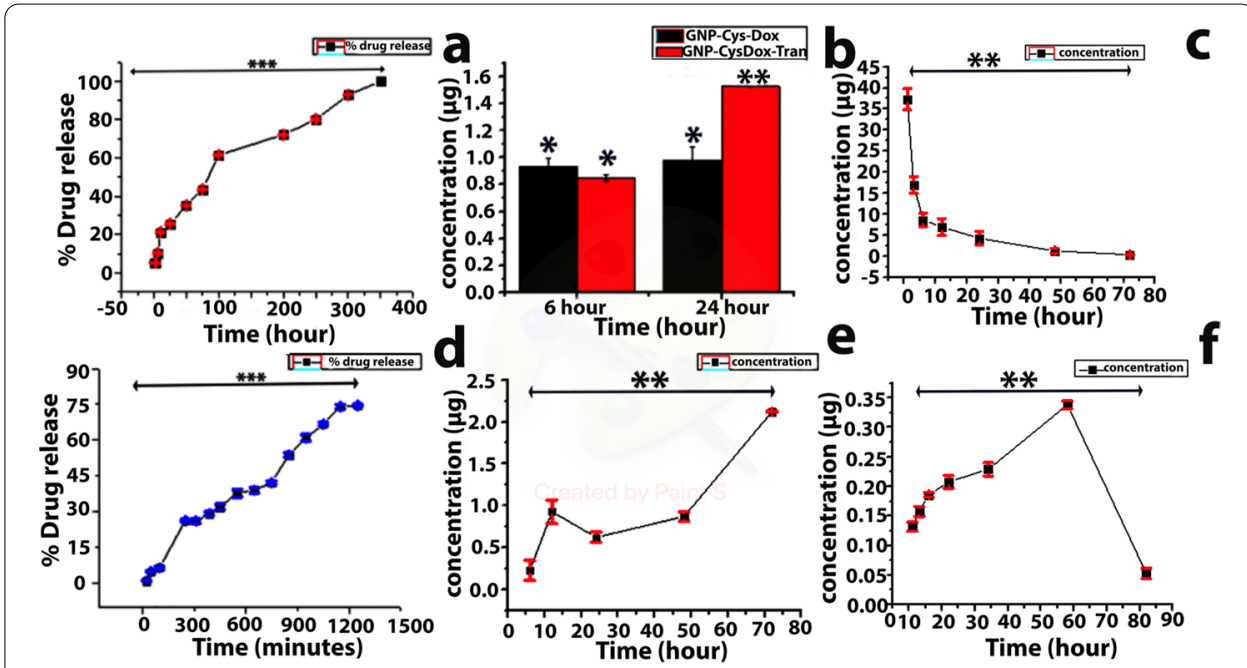

Fig. $8 \mathrm{pH}$-dependent doxorubicin releasing behaviour, and pharmacokinetics in vivo and in vitro. a At $\mathrm{pH}: 5$, half of the drug is released from nanocomposite in the releasing medium after $85 \mathrm{~min}$, while at $\mathrm{pH}$ : 7.5 half of the drug is released from nanocomposite in the releasing medium after $85 \mathrm{~min}$ (d). $\mathbf{b}$ Targeted delivery at $24 \mathrm{~h}$ shows the maximum concentration as compared to non-targeted delivery at $24 \mathrm{~h}$. At $6 \mathrm{~h}$ no significant difference was observed. e In vitro doxorubicin concentration in culture medium and dead cells after different time points (GNP theranostic nanomedicine). Results show the increase in concentration at $12 \mathrm{~h}$, then decreases a little. Maximum concentration is shown at $72 \mathrm{~h}$. c Olasma drug activity profile of doxorubicin (GNP theranostic nanomedicine) after IV administration at different time points and $\mathbf{f}$ plasma drug activity profile of doxorubicin (GNP theranostic nanomedicine) after PO. Data represented in mean $(n=3)$ with standard deviation and $p$ value $<0.001)$

bound to receptors and started to move inside the cellular compartments as soon as they came into contact with the surface. Figure 6a shows the nanomedicine binding and localization inside the cells after 3, 6 and $12 \mathrm{~h}$. Maximum drug was observed at tissue study after $12 \mathrm{~h}$ of oral dose. After $12 \mathrm{~h}$, the drug and nanoparticles started to dissipate from cells as shown by the reduction in fluorescence at 48 and $72 \mathrm{~h}$. At $72 \mathrm{~h}$, only traces were left in the tissue. Fluorescent intensities in tissues after the above-mentioned time points were measured by using image $J$ software at different fluorescent filters in sets of three, area of $67.17 \mathrm{~cm}^{2}$ and their means were compared statistically, as shown in Fig. 6b. These observations reinforced the previous finding of fluorescent studies of GNP theranostic nanomedicines and showed that the maximum binding to the receptor is at $6 \mathrm{~h}$, after which it begins to reduce. While nanoparticles of a size smaller than this were still present in cells as shown by blue emission filter intensity, most of the drug was eliminated from the tissue after $48 \mathrm{~h}$ as shown by the reduction in red fluorescence with nanoparticles approximately $30-50 \mathrm{~nm}$ (reduction in green fluorescence) in size. GNP of all sizes and doxorubicin, however, showed the same pattern of tissue localization and removal from the tissue.

\section{Effect of GNP and survival rate}

Anticancer efficacy of GNP theranostic nanomedicine was examined in three groups: saline, doxorubicin and GNP theranostic. These were observed during treatment for 40 days. The experiment was scheduled to last two months but terminated at 40 days due to the death of the last mouse in group two (receiving pure doxorubicin). The mice 
Table 1 Pharmacokinetic parameters of GNP theranostic nanomedicines after IV administration

\begin{tabular}{lll}
\hline Sr.\# & $\begin{array}{l}\text { Pharmacokinetics } \\
\text { Parameters }\end{array}$ & $\begin{array}{l}\text { Mean values } \\
(n=3)\end{array}$ \\
\hline 1 & $C^{\circ}(\mu \mathrm{g} / \mathrm{ml})$ & 176 \\
3 & $C_{\max }(\mu \mathrm{g} / \mathrm{ml})$ & $37.33 \pm 2.52$ \\
3 & $\mathrm{t}_{\max }(\mathrm{h})$ & 1 \\
4 & $\mathrm{t}_{1 / 2}(\mathrm{~h})$ & $12.70 \pm 1.75$ \\
5 & $\mathrm{AUC}(\mathrm{h} \cdot \mathrm{mg} / \mathrm{L})$ & $296.91 \pm 11.49$ \\
6 & $\mathrm{~K}\left(\mathrm{hr}^{-1}\right)$ & 0.05 \\
7 & $\mathrm{CL}(\mathrm{L} / \mathrm{h})$ & 0.001 \\
8 & $\mathrm{~V}_{\mathrm{d}}(\mathrm{L} / \mathrm{kg})$ & 0.0284 \\
9 & $\mathrm{P}$ value & $<0.001$ \\
\hline
\end{tabular}

treated with saline and GNP theranostic nanomedicine were active throughout the period of treatment when compared to the doxorubicin group. Though the theranostic nanomedicine group showed dizziness for a few hours after dosage administration, they became active after some time. Mice in group 2 became lethargic and weak day-by-day, while mice in group 1 were still active. The survival rate of group 1 began to reduce after some time and was $60 \%$ at the end of the study. Mice in group 2 showed zero \% survival at 40 days, while group 3 mice showed $80 \%$ survival rate with active lifestyle (Fig. 7a). The effect of the treatment on weight was observed in the first 15 days and results showed that mice in group three-treated with GNP theranostic nanomedicine-not only had a prolonged life, but also a healthy one with a smooth weight gaining pattern (Fig. 7b).

\section{Pharmacokinetics of GNP (in vitro)}

pH-dependent drug release

The drug release experiment was performed in acidic pH: 5 and neutral pH: 7.5 (in vitro). The purpose of the experiment was to check the kinetic release behaviour of the drug at different $\mathrm{pH}$ conditions. Acidic condition prevailed in tumour vicinity and stomach, while physiological $\mathrm{pH}$ of plasma and organs was almost 7.5. The $\mathrm{pH}$ of the nanomedicines containing medium was also 7.5; therefore, drug release behaviour was checked to see the drug stability and release at required sites.

Drug release behaviour of GNP theranostic nanomedicines at $\mathrm{pH} 5$ and 7.5 is shown in Fig. 8a, d. This behaviour confirmed the stability of theranostic nanomedicines at pH 7.5 and dominant releasing behaviour at acidic $\mathrm{pH}: 5$. The graph was plotted in percentage drug releases at different time intervals. Drug release behaviour showed that doxorubicin was released in free form, the drug release rate is greater at $\mathrm{pH} 5$ and the drug was stable at $\mathrm{pH}$ 7.5. These results also predicted the drug stability in vivo and release at tumour/cancer cells due to the $\mathrm{pH}$-dependent release. At $\mathrm{pH} 5$, half of the doxorubicin was released in $85 \mathrm{~min}$, while at pH 7.5 it took $850 \mathrm{~min}$ to release half of the conjugated doxorubicin.

\section{Release of doxorubicin from GNP}

In cell culture, the doxorubicin release was measured in two sets of reactions. In the first one, targeted versus non-targeted concentration was measured, and in the second, doxorubicin concentration in dead cells and media was measured at different time points 
Table 2 Pharmacokinetics parameters of GNP theranostic nanomedicines after PO administration

\begin{tabular}{lll}
\hline Sr\# & $\begin{array}{l}\text { *Pharmacokinetics } \\
\text { Parameters }\end{array}$ & $\begin{array}{l}\text { Mean values } \\
(n=3)\end{array}$ \\
\hline 1 & $C^{\circ}(\mu \mathrm{g} / \mathrm{ml})$ & 176 \\
2 & $C_{\max }(\mu \mathrm{g} / \mathrm{ml})$ & $0.338 \pm 0.006$ \\
3 & $t_{\max }(\mathrm{h})$ & 48 \\
4 & $\mathrm{AUC}(\mathrm{h} \cdot \mathrm{mg} / \mathrm{L})$ & $15.48 \pm 2.1$ \\
5 & $\mathrm{~V}_{\mathrm{d}}(\mathrm{L} / \mathrm{kg})$ & 0.0284 \\
6 & $p^{- \text {-value }}$ & $<0.001$ \\
\hline
\end{tabular}

$C^{\circ}$, initial plasma drug concentration at the time of injection; $C_{\text {max }}$ maximum plasma concentration at observed points; $t_{\text {max }}$ time at which the maximum concentration was noted; $t_{1 / 2}$, plasma half-life; $A U C$, area under the plasma concentration time profile curve; $\mathrm{K}$, elimination constant; $\mathrm{CL}$, clearance rate; $\mathrm{V}_{\mathrm{d}}$, distribution volume

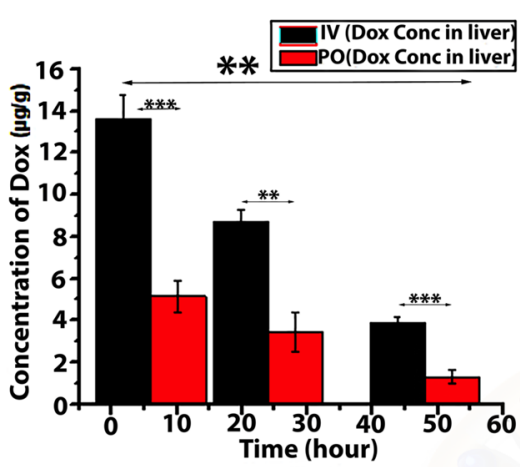

\section{a}
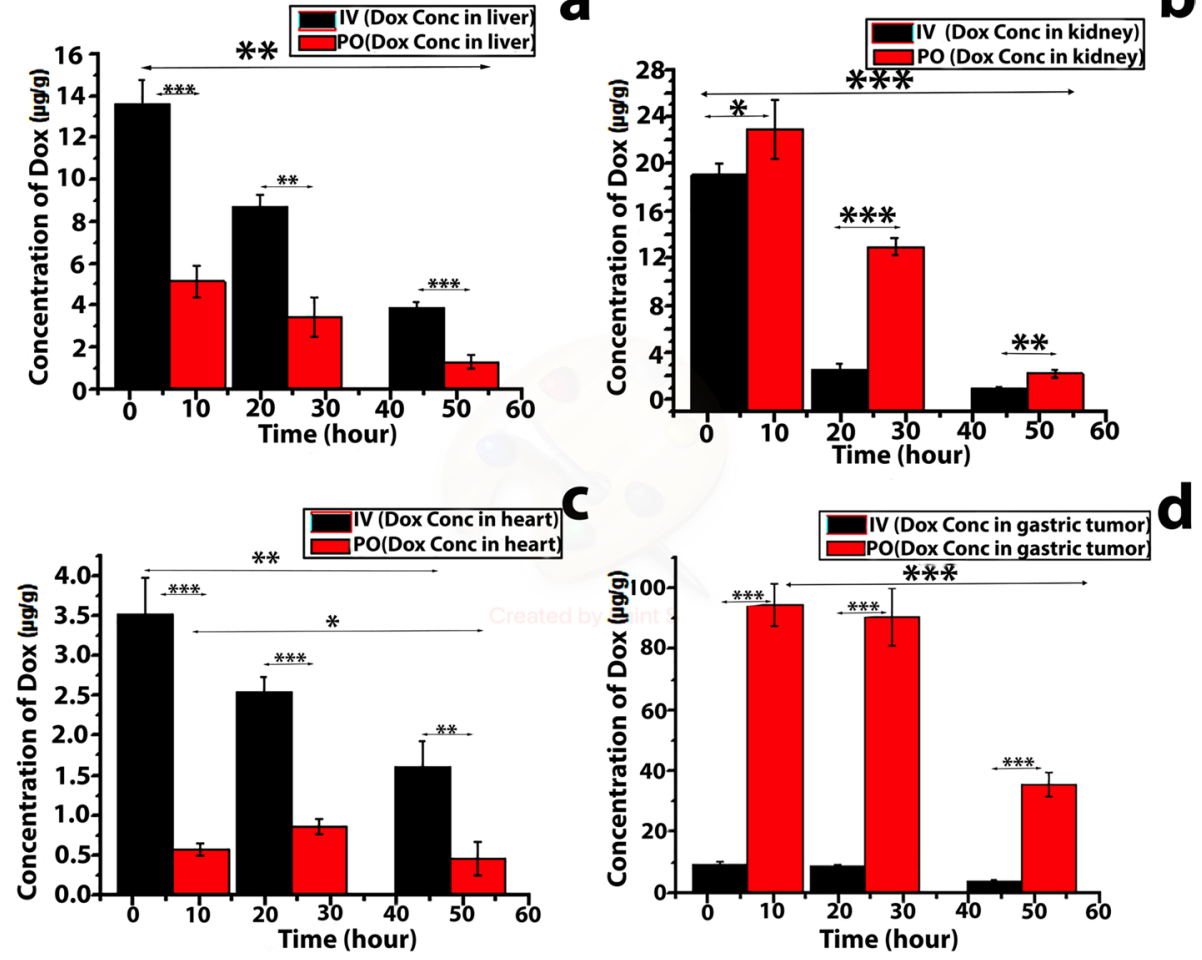

Fig. 9 Biodistribution comparison of doxorubicin from GNP theranostic nanomedicine in liver, kidney, heart and tumour after IV and PO dose, at different time points. a Graph confirmed the reduction of doxorubicin in liver tissue with the passage of time. $\mathbf{b}$ Doxorubicin eliminated from the heart quickly. c Doxorubicin concentration was decreased with time and showed quick elimination from the body. $\mathbf{d}$ Oral administration showed most of the drug was bound to the target site, while after IV administration only a little amount was able to reach at the targeted site but that little amount was able to show effect until $48 \mathrm{~h}$

by HPLC. Concentration of doxorubicin in dead cells of reaction incubated with GNPCys-Dox and in reactions with GNP-Cys-Dox-Trans was calculated at 6 and $24 \mathrm{~h}$. The values were compared by ANOVA. Significance was found in the group targeted to nontargeted at $24 \mathrm{~h}$ with $p$ value $<0.005$. Targeted GNP nanocomposites showed a higher 
doxorubicin concentration at $24 \mathrm{~h}$ than non-targeted GNP nanocomposite. The difference in concentration at $6 \mathrm{~h}$ was not dominant (Fig. 8b).

Doxorubicin concentration in media with dead cells was analysed with HPLC at different time points and compared by ANOVA. The maximum concentration of doxorubicin was found at $72 \mathrm{~h}$ and then at $12 \mathrm{~h}$. Minimum concentration was recorded at $6 \mathrm{~h}$, as shown in Fig. 8e. All reactions were done in triplicate and the data is represented as mean with standard deviation and significance value $<0.005$.

\section{Pharmacokinetics of GNP (in vivo)}

Blood activity time profile of doxorubicin release from GNP theranostic nanomedicine was studied in two groups. One group received nanomedicine through intravenous route (IV route) and the other through oral route. After administration of GNP theranostic nanomedicine from intravenous route, the drug profile in plasma was characterized with HPLC analysis. Analysis showed the data were at a significant interval $(p$ value $<0.001)$ as shown in Fig. 8c. All pharmacokinetics parameters were calculated by putting the values in the formula as summarized in Table 1. The clearance rate of GNP-Cys-Dox-transferrin was 0.002 $\mathrm{l} / \mathrm{h}$ and plasma half-life (t1/2) was $12.70 \mathrm{~h}$. Drug concentration in plasma decreased with the passage of time and a small amount of doxorubicin was observed at 48 and $72 \mathrm{~h}$.

Plasma concentration of doxorubicin was analysed by HPLC at different time points after oral administration (PO) too. Data are represented as mean $(n=3)$ with standard deviation and in significant intervals with $p$ value $<0.001$. Drug concentration in plasma was raised after the oral administration and reached its maximum concentration at $48 \mathrm{~h}$. From 48 to $72 \mathrm{~h}$, the concentration line showed a dramatic fall and led to the elimination of the drug from plasma (Fig. 8f). Pharmacokinetics parameters after the oral dose is summarized in Table 2.

\section{Biodistribution of GNP theranostic nanomedicine}

Biodistribution of doxorubicin after IV and oral administration was also examined. Doxorubicin concentration in liver, heart, kidney and gastric tumour was detected after IV as well as PO dose with a fluorescent scanner at 485 excitation and 525 emission (fluorescent microplate reader). Results confirmed the reduction of doxorubicin in liver tissue with the passage of time (Fig. 9a). Doxorubicin concentration in liver tissue after oral dose was lesser than IV at all time points and showed quick elimination from liver tissue. In case of the heart, Fig. 9c shows the doxorubicin concentration at different time points and confirms the elimination of doxorubicin from the heart quickly. The concentration of doxorubicin was lower in case of oral administration as opposed to IV. The kidney showed the elimination of doxorubicin from the body at different time points. Doxorubicin concentration decreased with time and showed quick elimination from the body (Fig. 9b). After oral administration, most of the doxorubicin was traced in the kidney and eliminated from the body, unlike intravenous administration. Biodistribution experiments were done in mice from gastric cancer model too. After IV administration, only a little amount was able to reach the targeted site; despite this, it was able to show effect until $48 \mathrm{~h}$. Oral administration showed that most of the drug was bound to the target site and, at $48 \mathrm{~h}$, a higher concentration was present in the gastric tumour portion (Fig. 9d). 


\section{Discussion}

Nanotechnology plays an important role in designing theranostic nanomedicines and helps to obtain a combination of diagnostic and therapeutic effect in one formulation. Different targeted approaches have been used for targeting drug delivery that not only helps in diagnosis or drug delivery to the affected area, but also supervises therapeutic responses (Nagaich 2015); (Eck et al. 2008). Studies have shown that a combination of traditional chemotherapeutic drugs and nanotechnology have an edge over traditional medicines (PD-L1 monoclonal antibody-conjugated nanoparticles enhance drug delivery level and chemotherapy efficacy in gastric cancer cells).

Recent drug delivery approaches have applied nanotechnology in the medicinal field to design new nanomedicines for effective drug delivery to gastric cancerous cells ( $\mathrm{Li}$ et al. 2017). GNP have been used as nanovehicles in many experiments due to their unique quantum confined fluorescent properties and binding abilities for theranostic nanomedicines. Although published data are available on GNP as a nanocarrier in different formulations and applications in different types of cancer (Xiao et al. 2012); (Aryal et al. 2009), there is still a big gap to fill.

In cancer treatment, the main problem that needs to be tackled is saving normal cells that otherwise leads to the disturbance/regulation of the normal physical system. Although some chemotherapeutic drugs such as doxorubicin have high antitumour activity, they are unable to differentiate between normal cells and cancer cells (Thorn et al. 2011); (Rivankar. xxxx). Doxorubicin (anticancer drug) penetrates to all cells easily due to its low molecular weight; however, it damages healthy cells along with normal cells. This main hurdle can be overcome with targeting drug delivery through nanocarriers (Luo and Prestwich 2005; Zhang et al. 2016). Therefore, to use doxorubicin as an anticancer drug with greater efficacy, drugs can be conjugated with a number of nanodeliveries (Moorthi et al. 2011). The therapeutic effect of doxorubicin can be increased by targeting cancer cells with ligands to specific surface receptors. Doxorubicin was conjugated with different nanocarriers such as magnetic nanoparticles and GNPs and examined against different types of cancers (Kayal and Ramanujan 2010); (Shafei et al. 2017); (Alexander et al. 2014).

Transferrin receptors' expression has attracted researchers for targeting drug delivery on rapidly growing cells (Iinuma et al. 2002). Transferrin is an important growth-promoting protein due to its iron-binding property (Ascione et al. 2010) and its expression is elevated in cancer cells due to increased uptake of iron in cancer cells for high metabolic pathways (Daniels et al. 2006b). Therefore, a positive correlation exists between cancer cells and transferrin receptor expression (Trowbridge and Omary 2006; Luria-Pérez et al. 2016; Kwok 2002).

In this research project, GNP theranostic nanomedicines were synthesized and characterized with different techniques. Published data is available on the application of GNP in different formulation and in different fields. GNP with doxorubicin (Cui et al. 2017) and doxorubicin with transferrin were examined in different formulations against different cancers after intravenous administration (Cui et al. 2017); (Zabielska-Koczywas et al. 2017). Herein, GNP theranostic nanomedicine formulation is novel and its application against gastric cancer is going to be reported for the first time. 
Some inorganic nanocarriers exhibited unique fluorescent properties that are confined within their smaller sizes. To get nanoparticles of smaller size, an optimization process is necessary to characterize the properties. GNPs were synthesized by using Turkevich method under hydro conditions and optimized by using different concentrations of gold salt and citric acid treatment (Turkevich et al. 1951). Different sizes of GNPs were observed during the optimization process and characterized with UV-Vis spectrophotometry, excitation and emission spectra, FTIR, DLS and TEM. Particles of different sizes exhibited different optical properties and are visible to the naked eye (Huang and El-Sayed 2010). The brick-red colour indicated that the GNP size was 5-10 $\mathrm{nm}$ in our laboratory conditions. Cysteine was used as linker on GNP nanocarriers-its carboxylic group was utilized to conjugate the chemotherapeutic drug doxorubicin (amide bond) and amine group was conjugated to transferrin (targeted ligand) through the hydrazine bond. Published data available on doxorubicin conjugated to GNP were on hydrazine bond conjugation that releases doxorubicin more rapidly in acidic $\mathrm{pH}$ and is stable in a slightly alkaline $\mathrm{pH}$ : 7.4. Hydrazine bond ensures releasing doxorubicin in the acidic environment of a tumour and keeps it stable at the physiological pH of blood. In this study, theranostic nanomedicines were exposed directly in the stomach's acidic environment; therefore, amide bond was used to release doxorubicin slowly and make sure it releases after binding of transferrin to its receptors for endocytosis. To prevent the release of doxorubicin before endocytosis, an addition strategy was adopted during development of GNP theranostic nanomedicine. Doxorubicin was conjugated to CysGNP earlier than transferrin. Doxorubicin size is smaller as compared to transferrin; therefore, transferrin forms the outer covering and gives shelter to doxorubicin.

GNP UV spectra showed maximum absorbance at $520 \mathrm{~nm}$, indicating that the size of nanoparticles is below $25 \mathrm{~nm}$ and that the width of peak (narrow) demonstrated the narrow size distribution. Single absorption characteristic peak of GNP was seen in the visible range of $510 \mathrm{~nm}-550 \mathrm{~nm}$ due to their surface plasmon resonance with maximum absorbance at $520 \mathrm{~nm}$. The width of the peak describes the particles size distribution (Philip 2008). Incorporation of cysteine on GNP increased the stability of nanoparticles and prevented particle aggregation with time. After incorporating cysteine on GNP, the absorption peak showed a little broadening in width and a little variation in maximum absorption. The peak of UV spectra depends on the size and uniform size distribution of particles (Luthuli et al. 2013). Doxorubicin was immobilized onto GNP-Cys by the carbodiimide method, and a new spectrum was obtained with a shift in the absorption spectrum of GNP. Two peaks were observed-one due to the organic group at $290 \mathrm{~nm}$ and the other due to the inorganic group at $510 \mathrm{~nm}$ (Khutale and Casey 2017). Broadening in the width of peak after conjugation shows the tiny increase in particle size, thereby indicating successful conjugation. Further conjugation of GNP-Cys-Dox with transferrin was done by the glutaraldehyde method and characterized by UV spectroscopy. The new spectrum peak showed a red shift with broadening in the inorganic peak. Results indicated a little increase in size and a change in size distribution.

FTIR analysis was further used to confirm the surface modification of nanovehicles. The peak distribution of graph confirmed the completion of citrate reduction of gold salt and formation of GNP. FTIR analysis also confirmed the successful conjugation at each step; in the linker attachment, for instance, the most important functional peak of $\mathrm{SH}$ 
group of cysteine disappeared and the carboxylic and amine group in GNP-Cys FTIR spectra appeared. Doxorubicin conjugation with GNP-Cys composites was confirmed with the disappearance of amine-related peak of doxorubicin and carboxylic-linked peaks of GNP-Cys composites. After conjugation with transferrin, the shift in old peaks and the appearance of new transferrin-related peaks was observed.

Size studies by DLS and TEM showed a minor difference in size analysis of both techniques. DLS analysis measures hydrodynamic size in liquid along with associated solvents, whereas TEM describes the size in dry form and is more accurate (Hinterwirth et al. 2013). Solvents may affect the size distribution of nanoparticles. Size analysis confirmed that the nanoparticles size was near $10 \mathrm{~nm}$ for GNP and bioconjugations caused an increase in size after each step; the final formulation size, however, was below $100 \mathrm{~nm}$. Fluorescent spectra showed a decrease in the intensity of the final formulation as compared to the initial nanoparticles when excited at specific wavelengths due to the increase in size and coating of nanoparticles. Further, GNP and nanomedicine were observed under different filters of fluorescent microscope to confirm their inherent fluorescent properties and they had sharp fluorescence under UV, blue and green excitation filters. That is in agreement with the previous reported studies of scientists (Walling et al. 2009).

To evaluate targeted drug delivery and efficacy of GNP theranostic nanomedicines against GI tract (gastrointestinal tract), it was tested against gastric cancer cells (in vivo) and colon cancer cell line (in vitro). Three objectives were designed to find the therapeutic properties of GNP theranostic nanomedicines. The objective of the first assay was to see whether nanovehicles have any toxic effect on the cells. Generally, nanovehicles have intrinsic properties to affect the cancer cells (Smith et al. 2008). Another aspect of this assay was to compare the toxic effect on cells by non-targeted nanomedicines (GNP-Cys-Dox) and targeted nanomedicines (GNP-Cys-Doxtransferrin). In vitro, only a little difference was observed between targeted nanocomposite and non-targeted nanocomposites. In in vitro evaluation, it is difficult to find difference between targeting and non-targeting drug delivery effect due to the presence of only one type of culture in one experiment. The development of co-culture is very difficult and not an exact representation of the natural in vivo environment. In vivo complex environment of normal cells and cancer cells targeting drug delivery have benefit over non-targeting drug delivery. In the second assay, IC50 and IC100 were observed in vitro at two time points ( 6 and $24 \mathrm{~h}$ ) on colon cancer cells with different concentrations of theranostic nanomedicines. IC50 for GNP theranostic nanomedicines was $10 \mu \mathrm{l}(5 \mu \mathrm{g} / \mu \mathrm{l})$ and IC100 was almost $50 \mu \mathrm{l}$. The third assay was designed to see the effect of nanomedicines at different time points $(6,12,24,48$ and $72 \mathrm{~h}$ ). The results strengthened our hypothesis of prolonged drug release and its effect due to drug delivery at specific site and nanoformulation. Cell fluorescent study at $72 \mathrm{~h}$ still showed the presence of nanoparticles and doxorubicin inside cells. Nanovehicles gave fluorescence in UV and blue excitation filters and doxorubicin gave fluorescence in the green excitation filter.

Theranostic nanomedicines were tested in vivo. The main goal was to deliver a sufficient amount of drug at the targeted site. In gastric cancer therapy, the environment and $\mathrm{pH}$ are the main hurdles in the treatment and delivery of medicines. For precise 
targeting therapy, the therapeutic agent should be very strong to cross the barriers of either $\mathrm{pH}$, cross the mucin layer, and prolong stay in stomach and oral delivery system. An intracellular tracking of nanomedicines (in vivo) confirmed the successful binding of transferrin with transferrin receptors and doxorubicin was delivered to cancer/ tumour cells. Synthesized nanomedicine successfully crossed all the above-mentioned hurdles and approached the targeted sites. Fluorescent studies further confirmed the presence of nanoparticles and doxorubicin in tissue for $72 \mathrm{~h}$ and supported the in vitro studies. Intracellular nanomedicine tracking studies are also useful in the prognosis, or prediction, of the therapeutic effect of the drug (Lammers et al. 2011). The effects of theranostic nanomedicines versus pure doxorubicin (in vivo) were checked on the mice' body weight and observation of their survival rate. Mice treated with pure doxorubicin showed a gradual decrease in body weight and all mice were dead within 40 days. Mice treated with theranostic nanomedicines showed almost $80 \%$ survival rate at the end of 40 days and a smooth increase was observed in the body weight of treated mice.

First, $\mathrm{pH}$-triggered drug release behaviours were examined (in vitro) at $\mathrm{pH}$ : 5.0 (gastric acidic $\mathrm{pH}$ ) and $\mathrm{pH}$ : 7.4 (physiological pH of blood). This study helped us analyse the releasing behaviour of doxorubicin and stability of nanomedicines at different $\mathrm{pH}$. Releasing behaviour of doxorubicin from nanomedicines strengthened our hypothesis of prolonged drug release even at acidic $\mathrm{pH}$ due to the drug conjugation to nanovehicles with amide bond. Both theranostic nanomedicines showed almost stable behaviour at pH: 7.4 and controlled prolonged drug release behaviour at $\mathrm{pH}: 5$. The observation reinforced the previous observations of other published studies with amide linkage (Khutale and Casey 2017).

The smooth drug release from nanomedicines for a long period of time is the main concern for cancer treatments. Controlled drug release prevents healthy cells from the toxic effect of chemotherapeutic drugs due to dose toxicity (Cui et al. 2017). Along with controlled drug release, another aspect of nanomedicines including biocompatibility and bioclearance should be known. According to size characterization, the nanovehicle size of GNP was equal to $10 \mathrm{~nm}$. Published studies reported that nanoparticles of size smaller than $30 \mathrm{~nm}$ are cleared from the body by kidney and phagocytotic scavengers (mononuclear phagocytic system [MPS]) of the liver and spleen (Malam et al. 2009). Transferrin was recycled and doxorubicin was used to kill the cells.

The pharmacokinetics parameters of theranostic nanomedicine was recorded and it was observed that theranostic nanomedicine had higher area under the curve value (AUC), greater plasma $T_{1 / 2}$ and lower body clearance rate as compare to free doxorubicin. Drug release study was conducted in vivo after intravenous (IV) and oral (PO) administration. Observations of in vivo studies also confirmed the prolonged and controlled drug releasing behaviour of both theranostic nanomedicines (the in vivo findings reinforced the in vitro findings). After $72 \mathrm{~h}$, both theranostic nanomedicines showed continuous release of doxorubicin but in smaller concentration. After an intravenous administration, doxorubicin concentration moved from higher to lower concentration (Lee 2011) while after oral administration, doxorubicin concentration increased with time and then started to decrease. 
Biodistribution studies of theranostic nanomedicines were conducted on induced gastric cancer mice after IV and oral dose. The high concentration of doxorubicin was observed in liver and kidney at $6 \mathrm{~h}$ but, with the passage of time, the concentration decreased in organs. At $48 \mathrm{~h}$, an effective clearance of theranostic nanoparticles and doxorubicin from organs was observed. Morphology study of organs confirmed that theranostic nanomedicines were not harmful to these organs. Traces of doxorubicin were tracked in heart that was cleared with time. The most important observation was the doxorubicin concentration to gastric tumour after IV and oral dose administration. After IV administration, only a limited number of nanomedicines were able to approach the gastric tumour. However, this little amount remained in the tissue for longer and slowly released the drug. Administration from oral route delivered the maximum concentration of drug to gastric tumour that was released slowly from the nanoformulation over a longer period of time.

\section{Materials and methods}

\section{Synthesis of GNP}

The GNPs were synthesized by Turkevich citrate reduction method (Turkevich et al. 1951). To select a suitable concentrations of gold salt and trisodium citrate, we evaluated a variety of different concentrations. For an optimized final reaction, $15 \mathrm{mM}$ of working solution was boiled on a hot plate $\left(100{ }^{\circ} \mathrm{C}\right)$ mixed with $1 \%$ trisodium citrate solution ( $3 \%$ of total volume). The reaction was continuously stirred until the appearance of a brilliant red colour.

\section{Attachment of cysteine with GNP}

About $0.25 \%$ of $0.2 \mathrm{mM} \mathrm{L-cysteine} \mathrm{solution} \mathrm{was} \mathrm{added} \mathrm{in} \mathrm{the} \mathrm{prepared} \mathrm{GNP} \mathrm{solu-}$ tion, followed by stirring (two $\mathrm{h}$ at $25^{\circ} \mathrm{C}$ ) and shielded without disturbance $(12 \mathrm{~h}$ ). Cysteine-attached GNP (GNP-Cys) was centrifuged (14,000 rpm for $40 \mathrm{~min}$ ) followed by pellet washing with deionized water.

\section{GNP-Cys and doxorubicin conjugation}

GNP-Cys and doxorubicin conjugation was performed by EDC carbodiimide (1-ethyl-3-[3-dimethylamino propyl) in which $20 \mathrm{mg} / \mathrm{ml}$ of EDC (pH: 6.4) and $50 \mathrm{mg}$ of GNP-Cys was taken in deionized water ( $\mathrm{pH}$ of 8 ). The mixture was (incubated in the dark for $30 \mathrm{~min}$ ) continuous shaking (100 rpm) followed by the addition of $1 \mathrm{ml}$ of carbodiimide $(10 \mathrm{mg} / \mathrm{ml})$ and doxorubicin $(50 \mathrm{mg})$, incubated for $2 \mathrm{~h}\left(\right.$ dark at $37^{\circ} \mathrm{C}$ at $100 \mathrm{rpm}$ ). The conjugated particles were separated and the nanocomposites were stored at $4{ }^{\circ} \mathrm{C}$.

\section{GNP-Cys-Dox and transferrin nanocomposites}

GNP-Cys-Dox and transferrin nanocomposite conjugation was achieved by the glutaraldehyde technique as described in the previous study (Shahzad Lodhi and Qadir Samra 2019). The nanocomposites were kept in storage buffer $\left(-20^{\circ} \mathrm{C}\right)$. 


\section{Gold nanocomposites characterization}

Surface chemistry, conjugation, shape, size and fluorescent properties of nanocomposites were studied by Fourier transform infrared spectroscopy (FTIR), UV-VIS spectrophotometry, dynamic light scattering analysis (DLS), transmission electron microscope (TEM) and fluorescent spectrophotometry, as described in the previous study (Shahzad Lodhi and Qadir Samra 2019). Nanocomposites were also immune characterized for conjugation confirmation by enzyme-linked immunosorbent assay (ELISA) and dot blot.

\section{ELISA}

In ELISA, two reactions were prepared in triplicate, one for doxorubicin conjugation confirmation and another for transferrin conjugation. GNP theranostic nanomedicine was coated and incubated $\left(1 \mathrm{~h}, 37^{\circ} \mathrm{C}\right)$ for blocking (5\% skim milk) and then half of the wells were treated with rabbit anti-doxorubicin antibodies (1:5000 dilution) and half with rabbit anti-transferrin for $1 \mathrm{~h}$. The wells were incubated $\left(45 \mathrm{~min}\right.$ at $\left.37^{\circ} \mathrm{C}\right)$ with mouse antirabbit horseradish peroxidase-conjugated antibody (1:8000 dilution). Colour was generated, applying a tetramethyl benzidine solution with $1 \% \mathrm{H}_{2} \mathrm{O}_{2}$.

\section{Immunodot blot}

Immunocharacterization was performed using $1 \mu$ of theranostic nanomedicines placed on nitrocellulose membranes, processed for both doxorubicin transferrin conjugations confirmation.

\section{In vitro therapeutic effects (colon cancer cell line HCT116)}

\section{Culture maintenance}

Colon cancer cell line HCT-116 was obtained from American Type Culture Collection $\left(\mathrm{ATCC}^{\circledR}\right)$, maintained at $37{ }^{\circ} \mathrm{C}$ and $5 \% \mathrm{CO}_{2}$ with $95 \%$ humidity level. The complete culturing medium contained $10 \%$ FBS, $1 \times$ penicillin/streptomycin solution (Thermo Scientific Cat\#15140122) in RPMI-1640 (Merck Cat\#8758). The culture was expanded and stored both in $80{ }^{\circ} \mathrm{C}$ freezers and liquid nitrogen containers in completer serum with 5\% DMSO.

\section{Sample identity}

The main drugs under our study were GNP-Cys and GNP doxorubicin (Dox) loaded derivatives. GNP theranostic nanomedicine and their intermediates GNP-Cys and GNP-Cys-Dox were analysed on colon cancer cell line (HCT-116) for anticancer properties.

\section{Cell surface binding potential of theranostic drugs}

The surface binding of theranostic nanomedicines was evaluated on cells grown on $1 \%$ gelatin (Sigma-Aldrich ${ }^{\circledR}$ Cat\#G9391) coated glass coverslips and by treating cells with $10 \mu \mathrm{l}$ of $5 \mu \mathrm{g} / \mathrm{ml}$ drug for $15 \mathrm{~h}$ time point in standard culturing conditions. The cells were washed with $1 \times$ PBS and fixed with $4 \%$ paraformaldehyde for $20 \mathrm{~min}$. The dried cell slides were mounted (immunomounting medium, Cat 622701) and observed 
under fluorescent microscope. The fluorescent intensity was calculated using image j. (https://imagej.nih.gov). A total of 20 cells were analysed for their fluorescence and drug binding for each sample. The standard deviation was calculated at different time points for comparison purpose. Red and green fluorescent were used to estimate the concentration of doxorubicin in each cell nanoparticles respectively.

\section{Estimation of drug cytotoxicity}

Cell viability was checked through trypan blue stain (Sigma-Aldrich ${ }^{\circledR}$ Cat\#6146-5G), prepared in $0.4 \%$ of $\mathrm{PBS}$ at $7.4 \mathrm{pH}$. The treated cells were counted under microscope. The number of total number of cells and blue stained cells were counted as follows.

$\%$ viable cells $=[1.00-($ number of blue cells/total number of cells $)] \times 100$

\section{Cytotoxicity assay}

The relative cytotoxicity was estimated to optimise two parameters.

\section{Different concentrations of drugs}

This experiment was conducted to select the best concentration for study. After $6 \mathrm{~h}$ as short period of treatment and $24 \mathrm{~h}$ as longer treatment period, different concentrations of drugs were used: $2.5 \mu \mathrm{l}, 5.0 \mu \mathrm{l}, 7.5 \mu \mathrm{l}, 10.0 \mu \mathrm{l}, 20.0 \mu \mathrm{l}$ and $100 \mu \mathrm{l}$ from $5 \mu \mathrm{g} / \mathrm{ml}$ stock solution of all nanocomposites. After treatment, live-dead assay was done by trypan blue staining assay as mentioned above.

\section{Different time periods of treatment}

The same experiment was repeated using a fixed drug dose of $10 \mu \mathrm{l} \mathrm{from} 5 \mu \mathrm{g} / \mathrm{ml}$ of stock solution for different time points of incubation: $6 \mathrm{~h}, 12 \mathrm{~h}, 24 \mathrm{~h}, 48 \mathrm{~h}$ and $76 \mathrm{~h}$, to evaluate the ideal time for treatment with theranostic medicines.

\section{Cell adhesion estimation by crystal violet staining}

The cell adhesion assay was done using the crystal violet staining principle in a 96-well tissue culture-treated plate. Almost 20,000 cells were loaded in each well and incubated for $24 \mathrm{~h}$ at the standard growth conditions mentioned above. After incubation, the nanoparticle intermediated-both loaded and unloaded-with doxorubicin were treated in a concentration of $2 \mathrm{ul}$ per well and incubated again for $24 \mathrm{~h}$ along with untreated wells. After incubation, the medium was removed and the cells were fixed with absolute ethanol for $30 \mathrm{~s}$. These fixed cells were loaded with $0.2 \%$ crystal violet solution and incubated at room temperature for 2 min before being washed multiple times with $1 \mathrm{x}$ PBS. The stained cells were de-stained using a de-staining solution (1\% Triton X-100) and incubated at $37{ }^{\circ} \mathrm{C}$ for $5 \mathrm{~min}$. Once the stained cells released colour, the quantification was done by taking absorbance at $570 \mathrm{~nm}$. 


\section{Neutral red uptake for relative cell viability}

Adhered cells were flooded with neutral red solution and washed $(1 \times \mathrm{PBS})$ in complete growth medium $\left(40 \mu \mathrm{g} / \mathrm{ml}\right.$, Merk $\left.{ }^{\circledR} \mathrm{Cat} \# 553-242\right)$, followed by incubation $(5 \% \mathrm{CO} 2$ and $87 \%$ humidity for $2 \mathrm{~h}$ at $\left.37^{\circ} \mathrm{C}\right)$. The cells were washed $(1 \times \mathrm{PBS})$ and media was removed followed by de-staining of cells. The optical density was calculated in 96 wells-plate at $570 \mathrm{~nm}$ in ELISA reader.

\section{Receptor binding efficiency on gastric tissue in vitro}

Before proceeding to in vivo studies, GNP theranostic nanomedicine binding efficiency to gastric tissue was examined in vitro as described in the previous study (Shahzad Lodhi and Qadir Samra 2019).

\section{In vivo theranostic nanomedicines efficacy}

The mice model of gastric cancer was used to observe the drug binding to gastric cancer cells and to evaluate the efficacy. The effect of the drug on survival rate, body weight, and activeness were recorded.

\section{Drug binding, release and fluorescent intensity (ex vivo)}

Mice were anaesthetized with $50 \mathrm{mg} / \mathrm{kg}$ of ketamine chloride and $5 \mathrm{mg} / \mathrm{kg}$ xylazine by intramuscular injection. Serum was separated, aliquoted, and stored at $-20{ }^{\circ} \mathrm{C}$. Theranostic nanomedicine (GNP) (5 mg/kg of doxorubicin) after $6,12,24,48$, and $76 \mathrm{~h}$ was administered to mice followed by dissection. The stomach was washed $(0.85 \% \mathrm{NaCl}$ solution) and cut open. Sections $(6-8 \mu \mathrm{m})$ were cut and placed on albumin-coated slides to observe in different excitation filter microscope. Fluorescent intensity was observed through ImageJ software. About $67 \mathrm{~cm}^{2}$ area was taken into account to measure the intensity, and the concentration of nanoparticles was estimated and doxorubicin in tissues at different time intervals.

\section{Effect of theranostic nanomedicines}

The treatment was started according to the body weight of mice. The mice of the gastric cancer models were divided into three groups, each containing ten and treated with theranostic nanomedicine, doxorubicin, and saline. Subgroups A and B were treated with saline and $5 \mathrm{mg} / \mathrm{kg}$ doxorubicin twice a week. Similarly, theranostic nanomedicines ( $5 \mathrm{mg} / \mathrm{kg}$ doxorubicin) in saline was orally administered to group C. All the groups were kept in observation for 45 days. Prior to the dose, body weight was recorded while the activities of the mice were also calculated on daily basis. Survival rate was checked from the animals that died during treatment.

\section{Pharmacokinetic study}

Pharmacokinetics of GNP theranostic nanomedicine was investigated in vitro and in vivo, using high-performance liquid chromatography (HPLC) and biodistribution in vital organs was observed with fluorescent plate reader in vivo. 


\section{Chromatographic instruments and conditions}

HPLC having pump module, DFL-120 detector and liquid chromatography (DLC-20) was applied as detector (UV-Vis). A C-18 chromatography column was used with a binary pump, consisting with inorganic (deionized water with $0.1 \%$ phosphoric acid) and organic phases (acetonitrile) mobile phase. Peaks and analyses were seen with UV-Vis detector (set at $255 \mathrm{~nm}$ ) and Star-Chrom software, respectively.

\section{Standards and samples preparation for HPLC}

Dulbecco's modified Eagle's medium (DMEM) supplemented with $10 \%$ heat was used for the in vitro study. Normal mice plasma was used for in vivo study to make standard solutions. The In vitro $(5 \mu \mathrm{g}, 2.5 \mu \mathrm{g}, 1 \mu \mathrm{g}, 0.7 \mu \mathrm{g}, 0.4 \mu \mathrm{g}, 0.16 \mu \mathrm{g}, 0.064 \mu \mathrm{g}, 0.026 \mu \mathrm{g}$, $0.016 \mu \mathrm{g})$ and in vivo $(50 \mu \mathrm{g}, 25 \mu \mathrm{g}, 10 \mu \mathrm{g}, 5 \mu \mathrm{g}, 1 \mu \mathrm{g}, 0.5 \mu \mathrm{g}, 0.1 \mu \mathrm{g}, 0.05 \mu \mathrm{g}, 0.02 \mu \mathrm{g})$ standards of concentrations were prepared in 1:4 ratio acetone precipitation and vacuumed dried. About $100 \mu \mathrm{l}$ of initial mobile phase was added in in vitro standards and samples. About $60 \mu \mathrm{l}$ of initial mobile phase was added in vivo standards and samples. Samples were injected and peaks were observed.

\section{Pharmacokinetics (in vitro)}

\section{Drug release}

GNP theranostic nanomedicines with doxorubicin ( $3 \mathrm{mg} / \mathrm{ml}$ in $1 \times \mathrm{PBS}$ (pH: 7.4) were taken in a dialysis bag and two $\mathrm{pH}$ slots in triplicate reaction. The mediums of different $\mathrm{pH}$ were stirred continuously with hang dialyzed bags at $37^{\circ} \mathrm{C}$ and $200 \mu \mathrm{l}$ was taken after each selected time point for HPLC observation.

\section{Doxorubicin release}

For assays, cells $\left(8 \times 10^{3}\right)$ were grown in culturing plates (6 wells). Drug release was observed in two assays in vitro. The first assay of drug release investigation was observed in targeted nanocomposites versus non-targeted. These later were observed with doxorubicin on nanocarriers only. In the second assay (in medium and dead cells), the drug releasing pattern was analysed at $6,12,24,48$ and $72 \mathrm{~h}$. About $10.0 \mu \mathrm{l}$ of nanocomposite was added and incubated $\left(37{ }^{\circ} \mathrm{C}, 5 \% \mathrm{CO}_{2}\right.$ and $85 \%$ humidity) for predetermined time points. Dead cells along with media were removed and samples were prepared for HPLC analysis.

\section{Pharmacokinetics}

Different time points $(1,3,6,12,24,48$ and $72 \mathrm{~h})$ were selected and the mice were divided into two groups. For intravenous administration, nanomedicines were injected through the tail vein $(5 \mathrm{mg} / \mathrm{kg})$ and slaughtered at selected time points. Blood was collected and plasma was isolated. The samples were prepared by acetone precipitation.

Doxorubicin $(5 \mathrm{mg} / \mathrm{kg})$ was given to mice through oral gavages and dissected at selected time points $(1,3,6,12,24,48$ and $72 \mathrm{~h})$. Blood was collected for plasma isolation sample preparation. 


\section{Biodistribution}

Drug biodistribution was investigated in mice model of gastric cancer. After administration of nanoparticles through oral gavages (PO) and tail vein, mice were dissected to collect liver, kidney, heart, and gastric tumour and preserved at $-20{ }^{\circ} \mathrm{C}$. Tissues samples were mixed with saline and $400 \mu \mathrm{l}$ of methanol was added with $100 \mu \mathrm{l}$ (4:1) ratio followed by centrifugation at (14,000 rpm for $10 \mathrm{~min})$. The aupernatant was mixed with $1 \times$ PBS and centrifuged ( $3 \mathrm{~min}$ at 14,000 rpm). The supernatant was observed in fluorescent plate reader.

\section{Conclusion}

Pharmacokinetic and biodistribution studies confirmed and strengthened our hypothesis of controlled drug release over a prolonged period without causing any toxicity to other vital organs of the body. The concept behind this hypothesis was to synthesize a formulation that prevents the distribution of anticancer drugs to all cells and tissues. It may cause a serious damage to healthy cells and tissue too. Nanovehicle applications enhance the drug-carrying capacity and maximized the drug delivery to the targeted organs. The successful targeted drug delivery was observed by targeting the transferrin receptors with transferrin for accumulation of the drug at the target site of cancer cells with very high copy number of transferrin receptors to capture the transferrin-linked GNPs. This approach of drug delivery spares the damage to normal cells which come in contact with drug loaded GNPs before the cancer cells and hence reduces the side effects traditionally associated with conventional anticancer chemotherapeutics in clinical use.

\section{Supplementary Information}

The online version contains supplementary material available at https://doi.org/10.1186/s12645-021-00098-4.

Additional file 1. Measurement, concentrations and characteristics of GNP theranosticnanomedicines.

\section{Acknowledgements}

The authors are thankful to IMBB for technical support.

Authors' contributions

Conception and design of the study: MSL, ZQS. Acquisition of data: MSL, MTK. Analysis and interpretation of data: MSL, SA. Drafting the article: MSL and MTK. Revising content: MTK. Final approval of the version: DQW, ZQS. All authors read and approved the final manuscript.

Funding

Dong-Qing Wei was supported by grants from the National Science Foundation of China (Grant Nos. 32070662, 61832019, 32030063), the Key Research Area Grant 2016YFA0501703 of the Ministry of Science and Technology of China, the Science and Technology Commission of Shanghai Municipality (Grant No.: 19430750600), as well as SJTU JiRLMDS Joint Research Fund and Joint Research Funds for Medical and Engineering and Scientific Research at Shanghai Jiao Tong University (YG2021ZD02). The computations were partially performed at the Pengcheng Lab and the Center for HighPerformance Computing in Shanghai Jiao Tong University.

Availability of data and materials

Data in this study have been attached as Additional file 1.

\section{Declarations}

Ethics approval and consent to participate

Not applicable.

Consent for publication

Not applicable.

Competing interests

The authors declare that they have no competing interests. 


\begin{abstract}
Author details
${ }^{1}$ Institute of Molecular Biology and Biotechnology (IMBB), The University of Lahore, Defence Road Lahore, Lahore Postal code: 58810, Pakistan. ${ }^{2}$ Institute of Biochemistry and Biotechnology, University of the Punjab, Lahore, Pakistan. ${ }^{3}$ State Key Laboratory of Microbial Metabolism, School of Life Sciences and Biotechnology, Shanghai, China. ${ }^{4}$ Joint Laboratory of International Cooperation in Metabolic and Developmental Sciences, Ministry of Education, Shanghai Jiao Tong University, Shanghai 200240, China. ${ }^{5}$ Peng Cheng Laboratory, Vanke Cloud City Phase I Building 8, Xili Street, Nashan District, Shenzhen, Guangdong 518055, People's Republic of China.
\end{abstract}

Received: 18 June 2021 Accepted: 22 September 2021

Published online: 09 October 2021

\title{
Reference
}

Alexander CM, Hamner KL, Maye MM, Dabrowiak JC (2014) Multifunctional DNA-Gold Nanoparticles for Targeted Doxorubicin Delivery. Bioconjug Chem 25:1261-1271

Aryal S, Grailer JJ, Pilla S, Steeber DA, Gong S (2009) Doxorubicin conjugated gold nanoparticles as water-soluble and pH-responsive anticancer drug nanocarriers. J Mater Chem. https://doi.org/10.1039/b914071a

Ascione E et al (2010) A simple method for large-scale purification of plasma-derived apo-transferrin. Biotechnol Appl Biochem. https://doi.org/10.1042/BA20100156

Chen F, Ehlerding EB, Cai W (2014) Theranostic Nanoparticles. J Nucl Med 55:1919-1922

Cho K, Wang X, Nie S, Chen ZG, Shin DM (2008) Therapeutic nanoparticles for drug delivery in cancer. Clin Cancer Res off J Am Assoc Cancer Res. 14:1310-1316

Cui T et al (2017) Performance of Doxorubicin-Conjugated Gold Nanoparticles: Regulation of Drug Location. ACS Appl Mater Interfaces. https://doi.org/10.1021/acsami.6b16669

Daniels TR, Delgado T, Helguera G, Penichet ML (2006a) The transferrin receptor part II: targeted delivery of therapeutic agents into cancer cells. Clin Immunol Orlando Fla 121:159-176

Daniels TR, Delgado T, Helguera G, Penichet ML (2006b) The transferrin receptor part II: Targeted delivery of therapeutic agents into cancer cells. Clin Immunol. https://doi.org/10.1016/j.clim.2006.06.006

Eck W et al (2008) PEGylated gold nanoparticles conjugated to monoclonal F19 antibodies as targeted labeling agents for human pancreatic carcinoma tissue. ACS Nano 2:2263-2272

Epidemiology of gastric cancer: global trends, risk factors and prevention. https://www.ncbi.nlm.nih.gov/pmc/articles/ PMC6444111\%.

Goldys EM, Sobhan MA (2012) Fluorescence of colloidal gold nanoparticles is controlled by the surface adsorbate. Adv Funct Mater 22:1906-1913

Hinterwirth $\mathrm{H}$ et al (2013) Comparative method evaluation for size and size-distribution analysis of gold nanoparticles. J Sep Sci. https://doi.org/10.1002/jssc.201300460

Huang X, El-Sayed MA (2010) Gold nanoparticles: Optical properties and implementations in cancer diagnosis and photothermal therapy. J Adv Res. https://doi.org/10.1016/j.jare.2010.02.002

linuma $\mathrm{H}$ et al (2002) Intracellular targeting therapy of cisplatin-encapsulated transferrin-polyethylene glycol liposome on peritoneal dissemination of gastric cancer. Int J Cancer. https://doi.org/10.1002/ijc.10242

Jones DT, Trowbridge IS, Harris AL (2006) Effects of transferrin receptor blockade on cancer cell proliferation and hypoxiainducible factor function and their differential regulation by ascorbate. Cancer Res 66:2749-2756

Kayal S, Ramanujan RV (2010) Doxorubicin loaded PVA coated iron oxide nanoparticles for targeted drug delivery. Mater Sci Eng C 30:484-490

Khutale GV, Casey A (2017) Synthesis and characterization of a multifunctional gold-doxorubicin nanoparticle system for pH triggered intracellular anticancer drug release. Eur J Pharm Biopharm. https://doi.org/10.1016/j.ejpb.2017.07.009

Kwok JC (2002) The iron metabolism of neoplastic cells: Alterations that facilitate proliferation? Crit Rev Oncol Hematol. https://doi.org/10.1016/S1040-8428(01)00213-X

Lammers T, Aime S, Hennink WE, Storm G, Kiessling F (2011) Theranostic nanomedicine. Acc Chem Res. https://doi.org/ 10.1021/ar200019c

Langer R (1998) Drug delivery and targeting. Nature 392:5-10

Lee KYJ (2011) Colloidal gold nanoparticles for cancer therapy: Effects of particle size on treatment efficacy, toxicology, and biodistribution. ProQuest Dissertations and Theses 23:45

Li R, Liu B, Gao J (2017) The application of nanoparticles in diagnosis and theranostics of gastric cancer. Cancer Lett 386:123-130

Luo Y, Prestwich G (2005) Cancer-Targeted Polymeric Drugs. Curr Cancer Drug Targets. https://doi.org/10.2174/15680 09023333836

Luria-Pérez R, Helguera G, Rodríguez JA (2016) Antibody-mediated targeting of the transferrin receptor in cancer cells. Bol Méd Hosp Infant México. https://doi.org/10.1016/j.bmhimx.2016.11.004

Luthuli SD, Chili MM, Revaprasadu N, Shonhai A (2013) Cysteine-capped gold nanoparticles suppress aggregation of proteins exposed to heat stress. IUBMB Life. https://doi.org/10.1002/iub.1146

Malam Y, Loizidou M, Seifalian AM (2009) Liposomes and nanoparticles: nanosized vehicles for drug delivery in cancer. Trends Pharmacol Sci. https://doi.org/10.1016/j.tips.2009.08.004

Moorthi C, Manavalan R, Kathiresan K (2011) Nanotherapeutics to overcome conventional cancer chemotherapy limitations. J Pharm Pharma Sci 2:45

Nagaich U (2015) Theranostic nanomedicine: Potential therapeutic epitome. J Adv Pharm Technol Res 6:1

Nanoparticles to Deal with Gastric Cancer. https://www.researchgate.net/publication/317950514_Nanoparticles_to_ Deal_with_Gastric_Cancer. 
PD-L1 monoclonal antibody-conjugated nanoparticles enhance drug delivery level and chemotherapy efficacy in gastric cancer cells. https://pubmed.ncbi.nlm.nih.gov/30587982/.

Philip D (2008) Synthesis and spectroscopic characterization of gold nanoparticles. Spectrochim Acta Part Mol Biomol Spectrosc. https://doi.org/10.1016/j.saa.2007.11.012

Rivankar. An overview of doxorubicin formulations in cancer therapy. https://www.cancerjournal.net/article.asp?issn= 0973-1482; year $=2014$; volume $=10$; issue $=4 ;$ spage $=853$; epage $=858$; aulast $=$ Rivankar.

Shafei A et al (2017) A review on the efficacy and toxicity of different doxorubicin nanoparticles for targeted therapy in metastatic breast cancer. Biomed Pharmacother 95:1209-1218

Shahzad Lodhi M, Qadir Samra Z (2019) Purification of transferrin by magnetic nanoparticles and conjugation with cysteine capped gold nanoparticles for targeting diagnostic probes. Prep Biochem Biotechnol 49:961-973

Singh R, Lillard JW (2009) Nanoparticle-based targeted drug delivery. Exp Mol Pathol 86:215-223

Smith AM, Duan H, Mohs AM, Nie S (2008) Bioconjugated quantum dots for in vivo molecular and cellular imaging. Adv Drug Deliv Rev. https://doi.org/10.1016/j.addr.2008.03.015

Sudimack J, Lee RJ (2000) Targeted drug delivery via the folate receptor. Adv Drug Deliv Rev 41:147-162

Thorn CF et al (2011) Doxorubicin pathways: pharmacodynamics and adverse effects. Pharmacogenet Genomics 21:440-446

Trowbridge IS, Omary MB (2006) Human cell surface glycoprotein related to cell proliferation is the receptor for transferrin. Proc Natl Acad Sci. https://doi.org/10.1073/pnas.78.5.3039

Turkevich J, Stevenson PC, Hiller J (1951) Synthesis of Gold Nanoparticles Turkevich method. Faraday Discuss. https://doi. org/10.13140/RG.2.2.15238.37449

Verma HN, Singh P, Chavan RM (2014) Gold nanoparticle: synthesis and characterization. Vet World 7:34

Walling MA, Novak JA, Shepard JRE (2009) Quantum Dots for Live Cell and In Vivo Imaging. Int J Mol Sci 10:441-491

Wolfbeis OS (2015) An overview of nanoparticles commonly used in fluorescent bioimaging. Chem Soc Rev 44:4743-4768

Xiao Y et al (2012) Gold nanorods conjugated with doxorubicin and cRGD for combined anti-cancer drug delivery and PET imaging. Theranostics. https://doi.org/10.7150/thno.4756

Zabielska-Koczywas K et al (2017) Doxorubicin conjugated to glutathione stabilized gold nanoparticles (Au-GSH-Dox) as an effective therapeutic agent for feline injection-site sarcomas - Chick embryo chorioallantoic membrane study. Molecules. https://doi.org/10.3390/molecules22020253

Zhang Y et al (2016) Co-delivery of doxorubicin and curcumin by pH-sensitive prodrug nanoparticle for combination therapy of cancer. Sci Rep. https://doi.org/10.1038/srep21225

\section{Publisher's Note}

Springer Nature remains neutral with regard to jurisdictional claims in published maps and institutional affiliations. 